\title{
Hot Extrusion Processing of Al-Li Alloy Profiles and Related Issues: A Review
}

\author{
Yongxiao Wang and Guoqun Zhao*
}

\begin{abstract}
Al-Li alloy is a new structural material with the advantages of lightweight and high strength. The extrusion profiles of $\mathrm{Al}-\mathrm{Li}$ alloy are widely used in aerospace and other fields, which can significantly reduce the weight of the aerospace equipment and improve their carrying capacity and service performance. Particular service conditions of structural components in aeronautical and space areas put forward strict requirements on microstructure, mechanical properties, and dimensional precision of Al-Li alloy profiles. Therefore, it places higher requirements on the shape forming and microstructure controlling of the Al-Li alloy profiles. The manufacturing process of the profiles involves billet homogenization, hot extrusion, solution and quenching treatments, artificial aging, and others. The parameters of each process as well as the die structure have important effects on the final performance of the profiles. This article summarizes the main applications and key mechanical properties of Al-Li alloy extrusion profiles. The technologies related to the manufacturing process of the extrusion profiles are summarized and analyzed. The related studies about the evolutions of the microstructure and mechanical properties during homogenization and extrusion processes are reviewed. The developments of the solid solution and quenching treatments as well as the aging strengthening technology for extruded Al-Li alloy profiles are also introduced. The scientific problems and key technologies that need to be solved in the manufacturing of Al-Li alloy extrusion profiles are presented, and the prospect for future development trends in these fields is given.
\end{abstract}

Keywords: Al-Li alloy, Extrusion profile, Extrusion process, Heat treatment, Microstructure, Mechanical property

\section{Introduction}

Al-Li alloys have many advantages, such as low density, high elastic modulus, high specific stiffness and strength, and good corrosion resistance. The use of $\mathrm{Al}-\mathrm{Li}$ alloys instead of conventional high-strength aluminum alloys can reduce the structural mass by $10 \%$ to $20 \%$ and increase the stiffness by $15 \%$ to $20 \%$, which is important in improving the performance and delivery efficiency of aerospace equipment and reducing fuel consumption [1-4]. Therefore, $\mathrm{Al}-\mathrm{Li}$ alloys are widely valued in aerospace fields and being found more and more applications recently.

\footnotetext{
*Correspondence: zhaogq@sdu.edu.cn
}

Key Laboratory for Liquid-Solid Structural Evolution \& Processing

of Materials (Ministry of Education), Shandong University, Jinan 250061, China
Up to now, the development of Al-Li alloys can be roughly divided into three stages, and the alloy products can also be classified as three generations [3, 5]. The first generation $\mathrm{Al}-\mathrm{Li}$ alloy was developed from the 1950s. The representative product is the 2020 alloy developed by Alcoa Inc. It has been successfully applied to the RA-5C warning aircraft. However, the applications of the first generation alloy stopped after the 1960s due to the defects of low ductility and high notch sensitivity and the high production cost [3, 6]. In the 1970s and 1980s, in response to the energy crisis, the second generation $\mathrm{Al}-\mathrm{Li}$ alloys were researched and developed in the former Soviet Union, United States, and France. The representative alloys include 1420, 2090, 8090, and 2091. These alloys contain more lithium (approximately $1.9 \mathrm{wt} . \%$ to $2.7 \mathrm{wt} . \%$ ), and the alloy density is further reduced. The second-generation $\mathrm{Al}-\mathrm{Li}$ alloys are successfully applied in aircraft by replacing the traditional 
high-strength aluminum alloy components, which have significant weight reduction effects. However, the high lithium content in this generation alloys also caused many performance shortcomings, such as low toughness, high anisotropy, poor weldability, and performance loss at thermal exposure $[1,3,7]$. In order to solve the problems, the third generation $\mathrm{Al}-\mathrm{Li}$ alloys were researched and developed in the late 1980s. By reducing the content of lithium in the alloy (reduced to $0.75 \mathrm{wt} . \%-1.8$ wt.\%), increasing the content of copper (increased to $2.6 \mathrm{wt} . \%-4.0 \mathrm{wt} . \%)$ and adding alloy elements, such as $\mathrm{Ag}, \mathrm{Zr}$, and Sc, the problems existing in the second-generation alloys were solved. The third-generation alloys show excellent properties such as low anisotropy, high strength, and good weldability, which therefore have been developed rapidly and applied widely. The representative products of the third-generation of $\mathrm{Al}-\mathrm{Li}$ alloys include 2195, 2196, 2297, 2397, 2099, 2199, 2198, 2050, $2055,2060,2076$, etc., which are widely used in the fuel tank of a space shuttle, load-bearing beam of spacecraft, skin, stringer, and floor of fighter and civil aircraft [1, $3,8]$. Besides, a series of aluminum-lithium alloys has also be developed by Russia, including $\mathrm{Al}-\mathrm{Cu}-\mathrm{Li}$ alloys $1450,1460,1464,1469$ as well as Al-Cu-Li alloys 1420 and 1421. In 2009, Roger Digby put forward the concept of the fourth-generation $\mathrm{Al}-\mathrm{Li}$ alloy [5]. Compared with the third-generation $\mathrm{Al}-\mathrm{Li}$ alloy, the $\mathrm{Li}$ content is further reduced and it has higher strength and fracture toughness. In recent years, Beijing Aeronautical Materials Research Institute has developed a new X2A66 Al-Li alloy, which exhibits high strength, high damage resistance, low anisotropy, good corrosion resistance, and excellent formability. This alloy exhibits typical characteristics of the fourth-generation $\mathrm{Al}-\mathrm{Li}$ alloy $[9,10]$.

The components of $\mathrm{Al}-\mathrm{Li}$ alloy are generally formed by thermoplastic deformation. The main forming methods include extrusion, rolling, and forging. The rolling process is mainly used to produce various plates, and there are many related studies on the rolling process and properties of $\mathrm{Al}-\mathrm{Li}$ plates [11-14]. The forgings of $\mathrm{Al}-\mathrm{Li}$ alloys are rarely concerned, which mainly used to manufacture heavy structural parts such as aircraft bulkheads [3]. The extrusion process can form the long and straight components with the same cross-section, which has many advantages, such as the simple forming process, flexible cross-section, high production efficiency, good surface quality, and near-net-shape forming.

In aerospace equipment, especially in the airframe structure, there are many long and straight components, such as stringers, floor beams, seat rails, and some stiffened panels, as shown in Figure $1[15,16]$. The extrusion process is the appropriate method for

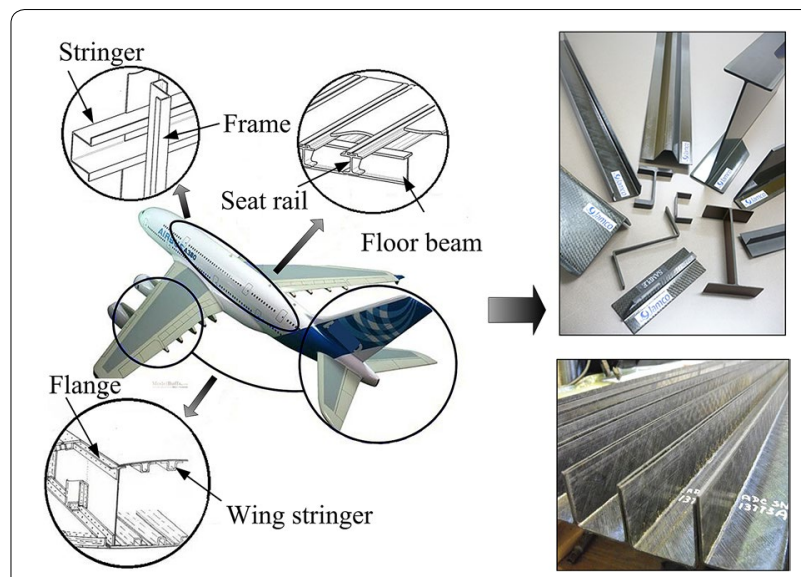

Figure $1 \mathrm{Al}-\mathrm{Li}$ alloy extrusion profiles can be used in aircraft

forming these components, which can greatly improve production efficiency and reduce material waste. In recent years, more and more structural parts in aircraft have been made of $\mathrm{Al}-\mathrm{Li}$ alloys to reduce the weight. Besides, as the cost in preparation of $\mathrm{Al}-\mathrm{Li}$ alloy materials reduces, the extrusion profiles of $\mathrm{Al}-\mathrm{Li}$ alloy would be gradually used in civilian fields, such as high-speed trains and automobiles. Therefore, Al-Li alloy profiles have a wide application future.

The main manufacturing process of $\mathrm{Al}-\mathrm{Li}$ alloy profiles includes the processes of hot extrusion and heat treatment. The evolution of microstructure in the processes is complex, which is related to the extrusion parameters, die structure, and heat treatment parameters, and determines the mechanical properties of the extrusion profiles. The manufacture of $\mathrm{Al}-\mathrm{Li}$ alloy profiles involves many scientific problems and key technologies, such as plastic deformation behavior, constitutive relationship, microstructure evolution, forming mechanism, welding mechanism, design of extrusion die, isothermal extrusion, and profile heat treatment. It is not only necessary to control the hot deformation behavior of the material to ensure the accurate forming of the profile, but also to control the microstructure to obtain good mechanical properties, i.e., the manufacture of $\mathrm{Al}-\mathrm{Li}$ alloy profiles needs to achieve the integrated controls of both the shape and property.

In this article, we first summarize the main applications and key mechanical properties of the Al-Li alloy extrusion profiles. Then the related scientific and technological research progresses in the homogenization treatment, extrusion forming, and heat treatment of the $\mathrm{Al}-\mathrm{Li}$ alloy profile are reviewed. At last, the problems and the further developments in the field of extrusion of $\mathrm{Al}-\mathrm{Li}$ alloy profiles are presented. 


\section{Application and Performance of Al-Li Alloy Extrusion Profiles}

\subsection{Application of Al-Li Alloy Extrusion Profiles}

There are many different grades of Al-Li alloys, among which some alloys are often used to make rolled plates, such as 2X97, 2X98, 2050 alloys. The rolled plates of alloys 2197, 2297, and 2397 have been successfully used in the bulkhead decks of F16 fighter [5]. Alloy 2198 plates are used to make fuel tanks for the Falcon 9 rocket, and 2050 thick plates are used to make the integral panels of the Airbus planes. Some alloy, such as 2196, are often used to be extruded into profiles, and there are also alloys can be universally used for rolling and extrusion, such as the alloys 2090, 8090, 2099, and 2055.

The extrusion profiles are widely used in the aircraft structural parts such as stringers in wings and fuselage, floor beams, seat rails, fuselage frames. The extrusion profiles of Al-Li alloys 2090 and 8090 were early used to manufacture some components of the EH101 helicopter. The extrusion profiles of third-generation Al$\mathrm{Li}$ alloys were used in the cabin floor beams, seat rails, and wing beams of the Airbus A380. The COMAC C919 aircraft also applied the extrusion profiles of 2099 and $2196 \mathrm{Al}-\mathrm{Li}$ alloys in the fuselage stringers, floor beams, seat rails, and other parts. Besides, some extruded parts are also used in aerospace equipment, such as the external fuel tank of the space shuttle and the main load-bearing longerons of the crew module in Orion spacecraft. Figure 2 shows several application examples of the Al-Li alloy extrusion profiles. Table 1 summarizes the applications of the first, second, and third-generation $\mathrm{Al}-\mathrm{Li}$ alloys extrusion profiles and lists the conventional aluminum alloy replaced or will be replaced by $\mathrm{Al}-\mathrm{Li}$ alloys $[1-3,5,17-19]$.
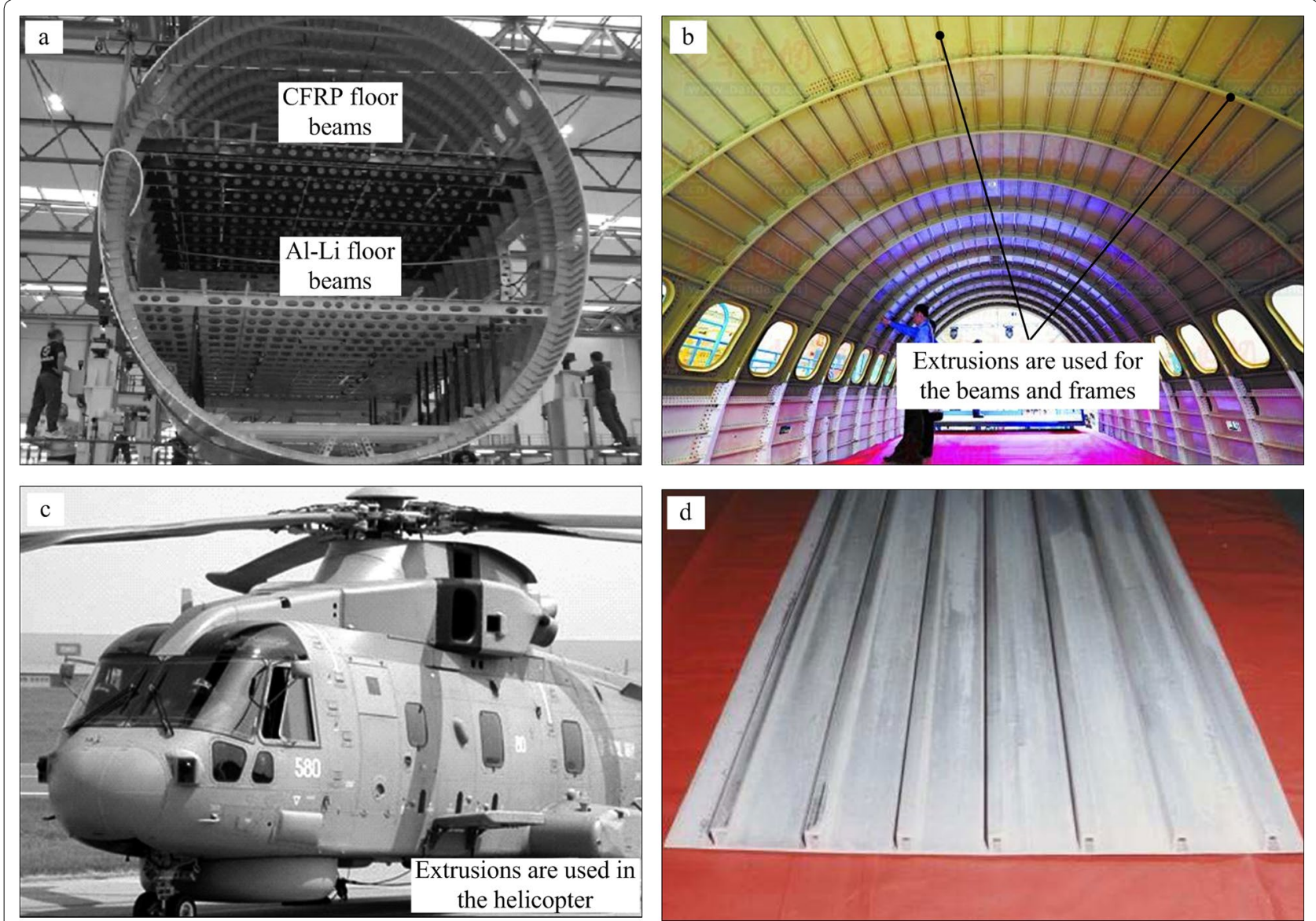

Figure 2 Applications of the Al-Li alloy profile in air and space equipment: a The third generation Al-Li alloy profile used for the floor beam of Airbus A380 aircraft [3], b Extrusion profile of 2099 and 2196 Al-Li alloys used in fuselage beams and frames of C919 aircraft, c Extrusion profile of $8090 \mathrm{Al}-\mathrm{Li}$ alloy used for the components of EH101 helicopter, $\mathbf{d}$ Extruded stiffened panel of $2090 \mathrm{Al}-\mathrm{Li}$ alloy used for the external fuel tank of space shuttle [18] 
Table 1 Applications of Al-Li alloy extrusion profiles and the replaced aluminum alloys [1-3, 5, 10, 17-19]

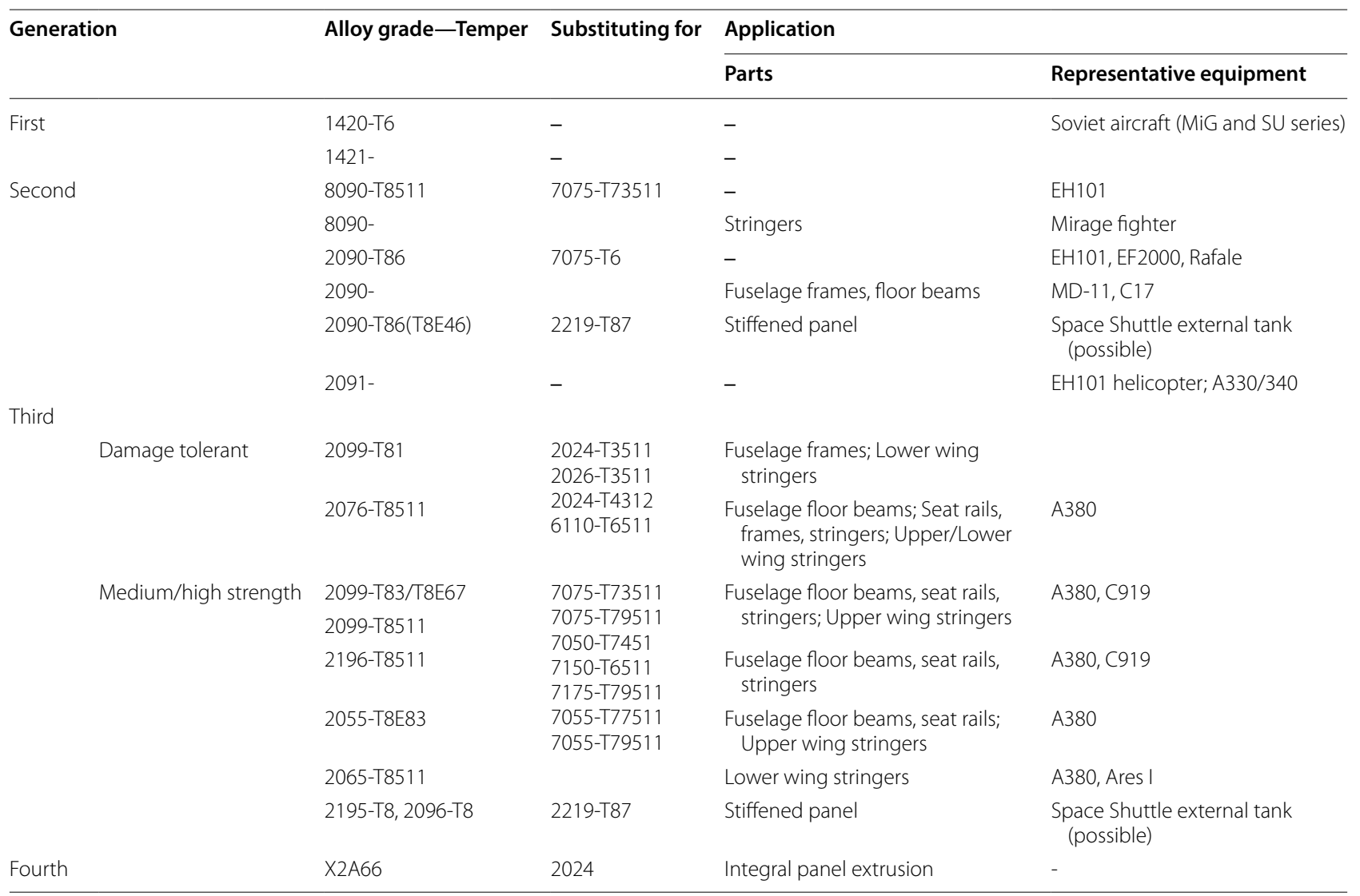

\subsection{Important Mechanical Properties of Al-Li Alloy Extrusion Profile}

Different parts in the aircraft bear different loads, so the extrusion profiles used in different parts have various requirements for the mechanical properties. Staley et al. [20] and Prasad et al. [3] summarized the main loads carried by various parts in the aircraft and the main performance requirements of the components. Longitudinal stringers and horizontal frame in the fuselage mainly bear tensile and compressive loads. Profiles used in these parts require high tensile and compressive strength, elastic modulus, and good damage tolerance (including fatigue life, fatigue crack growth rate, and fracture toughness). Floor beams and seat rails mainly bear tensile loads, which require high tensile strength and elastic modulus. Besides, the seat rails also require high resistance to stress corrosion. The loads on the wing are relatively complicated. The upper wing beams mainly bear compressive loads during flight, while the lower wing beams mainly bear tensile loads. Therefore, the high tensile and compressive strength, elastic modulus, and good damage tolerance are required for the profiles used in wings. In summary, the key mechanical properties required for
Al-Li alloy extrusion profiles used in aircraft include elastic modulus, tensile and compressive strength, and damage tolerance.

Table 2 summarizes the static mechanical properties of $\mathrm{Al}-\mathrm{Li}$ alloy extrusion profiles with various cross-sections in some existing literature. The dynamic mechanical properties, such as fatigue life, fatigue crack growth rate, and fracture toughness of the profiles cannot be simply listed in the table due to the different sample preparation standards and various experimental conditions. But some references about the dynamic properties are given in the table. Refs. [3, 7] also introduce the static and dynamic mechanical properties of different $\mathrm{Al}-\mathrm{Li}$ alloy components in more detail.

\section{Extrusion Process of Al-Li Alloy Profile \\ 3.1 Conventional Manufacturing Process of Extruded Profiles}

The equipment and processes for producing the conventional aluminum alloy extrusion profiles are usually also suitable for extrusion processing of $\mathrm{Al}-\mathrm{Li}$ alloys. However, the extrusion process of $\mathrm{Al}-\mathrm{Li}$ alloys also has its particularities. The extrusion profiles of most 
Table 2 Mechanical properties of Al-Li extrusion profiles

\begin{tabular}{|c|c|c|c|c|c|c|c|c|c|c|}
\hline \multirow[t]{2}{*}{ Alloy } & \multirow[t]{2}{*}{ Temper } & \multirow[t]{2}{*}{ Profile and testing positions } & \multirow{2}{*}{$\begin{array}{l}\text { Testing } \\
\text { orientation }\end{array}$} & \multirow[t]{2}{*}{$\mathrm{E}(\mathrm{GPa})$} & \multicolumn{3}{|c|}{ Strength (MPa) } & \multirow[t]{2}{*}{ EL (\%) } & \multirow[t]{2}{*}{ Ref. } & \multirow[t]{2}{*}{ Ref. for DMP } \\
\hline & & & & & TY & UTS & $\mathrm{CY}$ & & & \\
\hline 1420 & - & & L & 76.4 & 312 & 432 & - & 10.2 & [21] & [21] \\
\hline \multirow[t]{2}{*}{2090} & T6 & & L & - & $\sim 750$ & - & - & - & [22] & {$[23,24]$} \\
\hline & & & $L$ & - & $\sim 630$ & - & - & - & & \\
\hline \multirow[t]{3}{*}{8090} & T6 & & L & - & $\sim 550$ & - & - & - & [22] & \\
\hline & & & L & - & $\sim 440$ & $\sim 515$ & - & - & {$[25]$} & \\
\hline & & & L & - & $\sim 420$ & $\sim 500$ & - & - & & \\
\hline \multirow[t]{3}{*}{8091} & T6 & & L & - & $\sim 630$ & - & - & - & {$[22]$} & \\
\hline & & & L & - & $\sim 495$ & $\sim 555$ & - & - & [25] & \\
\hline & & & L & - & $\sim 440$ & $\sim 510$ & - & - & & \\
\hline
\end{tabular}


Table 2 (continued)

\begin{tabular}{|c|c|c|c|c|c|c|c|c|c|c|}
\hline \multirow[t]{2}{*}{ Alloy } & \multirow[t]{2}{*}{ Temper } & \multirow[t]{2}{*}{ Profile and testing positions } & \multirow{2}{*}{$\begin{array}{l}\text { Testing } \\
\text { orientation }\end{array}$} & \multirow[t]{2}{*}{$\mathrm{E}(\mathrm{GPa})$} & \multicolumn{3}{|c|}{ Strength (MPa) } & \multirow[t]{2}{*}{ EL (\%) } & \multirow[t]{2}{*}{ Ref. } & \multirow[t]{2}{*}{ Ref. for DMP } \\
\hline & & & & & TY & UTS & $\mathrm{CY}$ & & & \\
\hline \multirow[t]{10}{*}{2099} & T83 & & L & - & $\sim 600$ & $\sim 630$ & 622 & - & {$[26,27]$} & {$[28,29]$} \\
\hline & & & $45^{\circ}$ & - & $\sim 475$ & $\sim 425$ & 472 & - & & \\
\hline & & & $\mathrm{T}$ & - & $\sim 445$ & $\sim 505$ & 435 & - & & \\
\hline & & & $L$ & - & $\sim 475$ & $\sim 535$ & 483 & - & & \\
\hline & & 19 & & & & & & & & \\
\hline & & & $45^{\circ}$ & - & $\sim 425$ & $\sim 480$ & 393 & - & & \\
\hline & & & $\mathrm{T}$ & - & $\sim 455$ & $\sim 505$ & 520 & - & & \\
\hline & & & L & - & $\sim 590$ & $\sim 600$ & 561 & - & & \\
\hline & & & $45^{\circ}$ & - & $\sim 445$ & $\sim 485$ & 397 & - & & \\
\hline & & & T & - & $\sim 490$ & $\sim 525$ & 445 & - & & \\
\hline \multirow[t]{2}{*}{2196} & T8511 & & $L$ & 73.17 & 519.93 & 592.23 & - & 6.97 & [30] & \\
\hline & & & L & 79.85 & 526.97 & 602.08 & - & 7.35 & & \\
\hline \multirow[t]{7}{*}{2195} & T83 & & L & - & $\sim 620$ & $\sim 645$ & - & $\sim 10.5$ & [31] & {$[31,32]$} \\
\hline & & & $45^{\circ}$ & - & $\sim 500$ & $\sim 540$ & - & $\sim 9$ & & \\
\hline & & & $\mathrm{T}$ & - & $\sim 520$ & $\sim 560$ & - & $\sim 8$ & & \\
\hline & & & $L$ & - & $\sim 580$ & $\sim 600$ & - & $\sim 11$ & & \\
\hline & & 3.4 & & & & & & & & \\
\hline & & 7.5 & & & & & & & & \\
\hline & & & $\mathrm{T}$ & - & $\sim 590$ & $\sim 640$ & - & $\sim 13$ & & \\
\hline
\end{tabular}

Key to Abbreviations: E-Elastic Modulus; TY-Tensile yield strength; UTS-Ultimate tensile strength; CY-Compressive yield strength; EL- Elongation Testing orientation: L- Extrusion direction; T- Perpendicular to the extrusion direction

The positions marked by the red circle are the sampling locations for performance testing

third-generation $\mathrm{Al}-\mathrm{Li}$ alloys cannot be quenched online because the extrusion temperature is lower than the quenching temperature. Besides, based on the dislocation nucleation mechanism of precipitates, the extrusion profiles of $\mathrm{Al}-\mathrm{Li}$ alloys require a certain amount of cold deformation before aging treatment to improve their performance. Some kinds of $\mathrm{Al}-\mathrm{Li}$ alloy are sensitive to extrusion temperature and speed, and the range of the process parameters is narrow. The defects such as surface cracking and performance degradation can be caused by the improper extrusion process. Therefore, more precise control of the extrusion process for the $\mathrm{Al}-\mathrm{Li}$ alloys is required. 


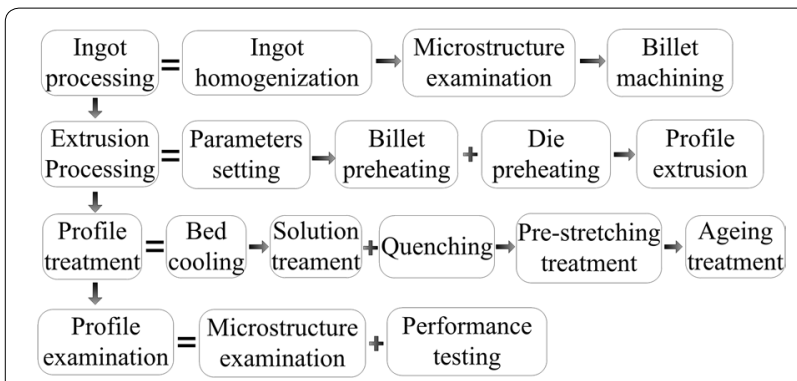

Figure 3 Common processes for producing the Al-Li alloy extrusion profiles

Skillingbers et al. [22] conducted extrusion experiments on four kinds of second-generation $\mathrm{Al}-\mathrm{Li}$ alloys including 2090, 2091, 8090, and 8091. They first homogenized the ingots and then machined them into round billets of appropriate size. The machined billet was preheated before extrusion and then extruded on a horizontal hydraulic press. The extruded profile was fan cooling on a cold bed. Subsequently, a formal out-line solution and quenching treatment were carried out on the extrusion profiles. The pre-stretching was applied to the solution treated profiles for improving the mechanical properties. Finally, the profiles were aged to the required state. Using similar processes, Kumar et al. [33] and Armanie et al. [34] also extruded the different Al-Li alloys. Therefore, it can be concluded that the extrusion forming process of $\mathrm{Al}-\mathrm{Li}$ alloys generally includes ingot homogenization, extrusion forming, solution treatment, pre-stretching, and artificial aging treatment. Figure 3 shows the process route for producing $\mathrm{Al}-\mathrm{Li}$ alloy extrusion profiles.

\subsection{Extrusion Process of the Stiffened Panel with Large-Size}

Sometimes, particular components need to be formed by the extrusion process, in which the special extrusion

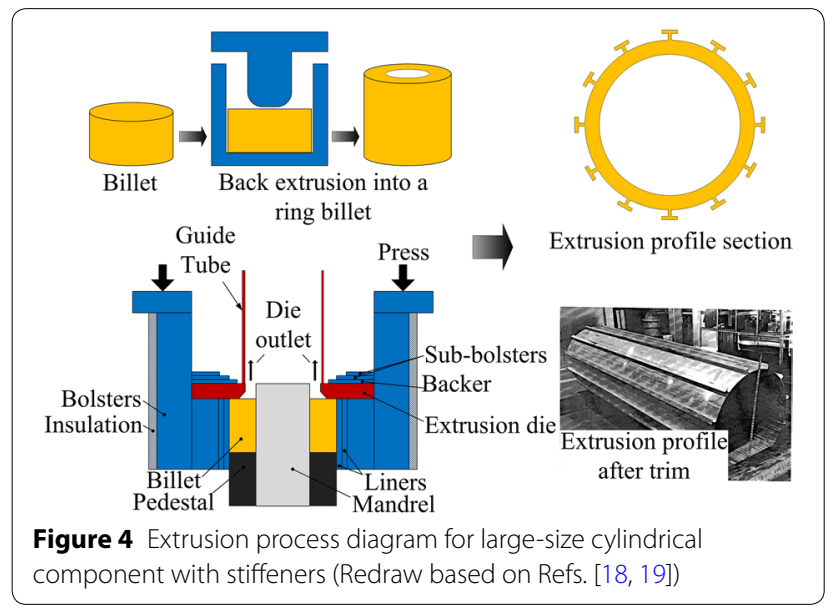

equipment, dies, and processes are required. As shown in Figure 2(d), the stiffened panel used for the external fuel tank of the space shuttle was usually fabricated by cutting the thick plate. However, the material waste rate of this method is as high as $90 \%$, so that the production cost is very high. This problem can be solved by the extrusion process which can achieve the near-net-shape forming. Nevertheless, the conventional extrusion equipment and processes cannot produce the stiffened panel due to its maximum width up to $2.5 \mathrm{~m}$. Therefore, it is necessary to develop a new extrusion process to manufacture such components.

In order to achieve the extrusion, the stiffened panel is first changed into a cylindrical component with stiffener $[18,19]$. The cylindrical component is extruded with a hollow billet, which is carried out on a hydraulic press with mold core. The extruded cylindrical component is cut along the extrusion direction and then flattened to obtain the required stiffened panel. Figure 4 shows the schematic diagram of the extrusion process. The heat treatment process of the stiffened panel, especially the pre-stretching treatment, is also complicated. The spacing between the stiffeners needs to be filled with another aluminum alloy to form an approximately complete plate, so that the pre-stretching deformation can be applied uniformly to both the panel base and the stiffeners. The uniform pre-stretching deformation can also reduce the residual stress inside the component as much as possible. Although this method has a certain effect, it is still difficult to obtain a uniform amount of pre-stretching deformation at each position of the stiffened panel.

The stiffened panels with medium width (about 1-1.6 $\mathrm{m})$ can be extruded by a common forward extrusion process with a round billet or slab billet [35]. Compared with the round billet, the slab billet presents a more uniform material flow during the extrusion of the panels, which can improve the uniformity of the microstructure and the performance. However, the design and manufacture of the container for the slab billet are more complicated than that for the round billet.

\section{Influence of Manufacturing Processes on the Microstructure and Properties of Al-Li Alloy Profiles}

The manufacturing process of $\mathrm{Al}-\mathrm{Li}$ alloy profiles includes homogenization treatment of the billet, extrusion forming of the profile, and solid solution and aging treatments of the extruded profile. The microstructural evolutions of the extrusion profiles are significantly affected by these processes, and the final mechanical properties of the profile also depend on the processes. The following describes the effects of each manufacturing process on the microstructure and properties. 


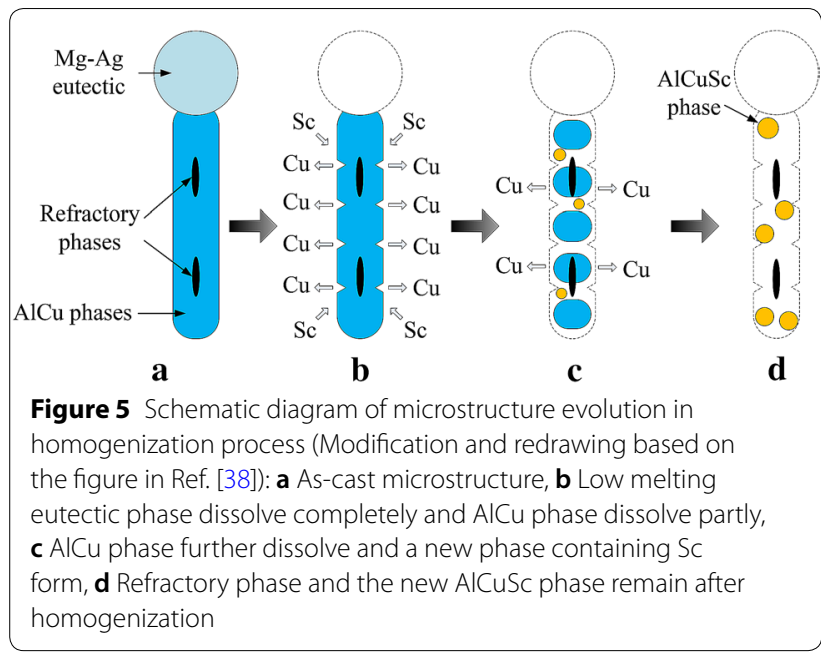

\subsection{Homogenization of Al-Li Alloy Billet}

The homogenization of billet, on one hand, is to eliminate the non-equilibrium eutectic phases, intragranular segregation, and casting stress in the ingot. After the homogenization, the microstructure uniformity and workability of the billet can be improved significantly. On the other hand, the homogenization process plays an important role in the precipitation of the dispersoids, which will affect the recrystallization behavior during the following hot deformation. Therefore, the homogenization process will have an important impact on the microstructure and mechanical properties of the extrusion profiles.

In the homogenization process, the low melting eutectic phases (such as the phases containing $\mathrm{Mg}$ and $\mathrm{Ag}$ ) will be dissolved firstly, and the network or dendrite structure in the as-cast billet gradually disappears. As the homogenization temperature and the time increases, the secondary particles with a slightly higher solution temperature (such as the $\mathrm{AlCu}$ phases) are also gradually dissolved into the matrix. After homogenization, a small amount of refractory phase (such as the phases containing Fe and $\mathrm{Si}$ ) will remain at the grain boundaries [36-38]. Wang et al. [39] studied the microstructure of spray-formed 2195 $\mathrm{Al}-\mathrm{Li}$ alloy before and after the homogenization. They found the microstructure of the spray-formed alloy after homogenization is similar to that of casting alloy, even though the initial microstructure of the sprayed alloy is different from that of the as-cast alloy. Jia et al. [38] studied the microstructure evolution of $1469 \mathrm{Al}-\mathrm{Li}$ alloy containing Sc during the homogenization process, and they found a kind of AlCuSc phase (termed as W phase) can form at the grain boundaries. During the homogenization at high temperature, the $\mathrm{Mg}-\mathrm{Ag}$ eutectic phases and $\mathrm{AlCu}$ phases are dissolved through element diffusion, while the solute $\mathrm{Sc}$ diffuses into the residual $\mathrm{AlCu}$ phases

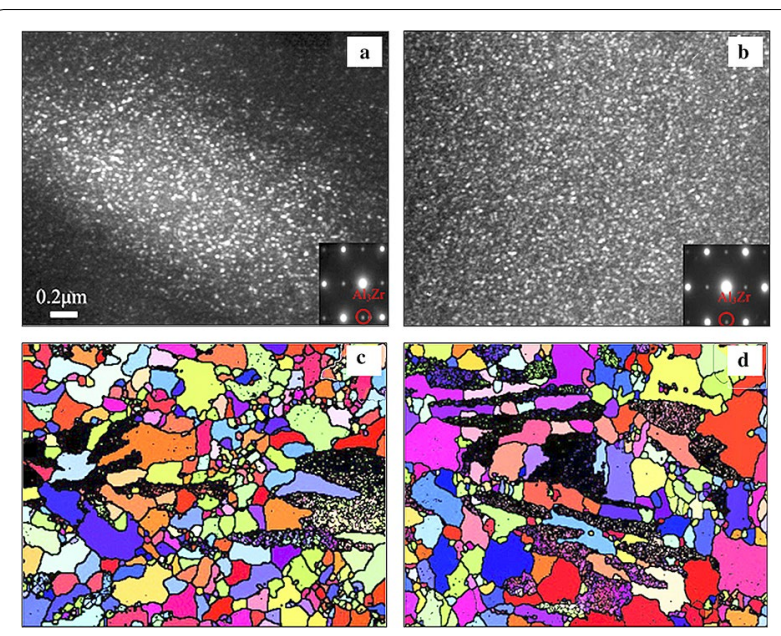

Figure 6 Precipitation characteristics of the $\mathrm{Al}_{3} \mathrm{Zr}$ phase after a single homogenization $\left(510^{\circ} \mathrm{C} / 24 \mathrm{~h}\right)$ and $\mathbf{b}$ two-stage homogenization $\left(460^{\circ} \mathrm{C} / 12 \mathrm{~h}+520^{\circ} \mathrm{C} / 24 \mathrm{~h}\right)$, and the recrystallization behavior after hot deformation of $\mathbf{c}$ the single homogenized sample and $\mathbf{d}$ two-stage homogenized samples (Reproduced from Ref. [41])

and forms the $\mathrm{W}$ phase that remains after the homogenization process. Figure 5 shows a microstructure evolution diagram during the homogenization of the $\mathrm{Al}-\mathrm{Cu}-\mathrm{Li}$ alloys containing elements of $\mathrm{Mg}, \mathrm{Ag}$, and Sc.

The mechanical properties of $\mathrm{Al}-\mathrm{Li}$ alloy profiles are closely related to the microstructure. The grain morphology, size, and orientation have important influences on the strength, toughness, and anisotropy of the profiles. For the third-generation Al-Li alloys, Rioja et al. [1] and Goma et al. [28] indicated that the fibrous grain structure without recrystallization is beneficial to improve the mechanical properties of the extruded profiles. The thirdgeneration $\mathrm{Al}-\mathrm{Li}$ alloys usually contain elements such as $\mathrm{Zr}$ and $\mathrm{Sc}$, which can form $\mathrm{Al}_{3} \mathrm{Zr}(\mathrm{Sc})$ dispersoids during the homogenization process. These dispersoids have a strong inhibitory effect on recrystallization. The size and distribution of the dispersoids depend on the homogenization parameters. It has been proved that a two-stage homogenization treatment can promote the dense and uniform precipitation of the dispersoids, which have a significant inhibition to the later recrystallization behavior [40, 41]. Two-stage homogenization usually includes a low-temperature stage and a subsequent high-temperature stage. In the low-temperature stage, the supersaturation of $\mathrm{Zr}$ in the matrix is very high and has strong precipitation kinetics, which promotes the dense nucleation of $\mathrm{Al}_{3} \mathrm{Zr}$. The diffusion rate of $\mathrm{Zr}$ at the low temperature is very slow, thus avoiding the rapid coarsening of $\mathrm{Al}_{3} \mathrm{Zr}$. Therefore, dense and fine $\mathrm{Al}_{3} \mathrm{Zr}$ will be formed in the matrix at the low-temperature stage. And the subsequent high-temperature stage, the $\mathrm{Al}_{3} \mathrm{Zr}$ dispersoids 
will grow up appropriately in size, thus having a stronger pinning effect. Figure 6 shows the precipitation characteristics of $\mathrm{Al}_{3} \mathrm{Zr}$ in $\mathrm{X} 2 \mathrm{~A} 66 \mathrm{Al}-\mathrm{Li}$ alloy samples after single and two-stage homogenization. As can be seen, the precipitation of dispersoids is more dense and uniform in the sample with two-stage homogenization. After hot deformation, the microstructures of the homogenized samples are shown in Figure 6(c) and (d). It can be seen that the dense and uniform $\mathrm{Al}_{3} \mathrm{Zr}$ phase in the two-stage homogenized sample has a stronger inhibitory effect on the recrystallization.

It has been found that the $\mathrm{Al}_{3} \mathrm{Zr}$ phase prefers to precipitate at dislocations and some existing phases (such as $\left.\mathrm{Al}_{2} \mathrm{Cu}\right)[42,43]$. Based on the precipitation mechanisms, it is reasonable to expect that the uniform and dense precipitation of the dispersoid can be promoted by some treatments such as pre-deformation and pre-aging before homogenization. However, such kinds of homogenization for $\mathrm{Al}-\mathrm{Li}$ alloys have not been studied.

\subsection{Evolutions of Microstructure and Mechanical Properties During the Al-Li Alloys Extrusion 4.2.1 Effects of Extrusion Process on Microstructure and Properties}

The important extrusion processing parameters include temperature, ram speed, and extrusion ratio, all of which influence the microstructural evolutions such as dynamic recovery (DRV), dynamic recrystallization (DRX), and grain deformation. The change of processing parameters will have a great influence on the microstructure of the $\mathrm{Al}-\mathrm{Li}$ alloy profiles such as grain morphology and its orientation, which in turn affect the mechanical properties of the profiles.

Mukhopadhyay et al. [44] carried out extrusion experiments on $8090 \mathrm{Al}-\mathrm{Li}$ alloy, and they found that the microstructure of the extrudate is not uniform. The surface layer of the extrudate is fully recrystallized, whereas the core exhibits essentially unrecrystallized grains. The thickness of the recrystallization layer increases with extrusion temperature, ram speed, and extrusion ratio, where the extrusion ratio has the most obvious effect on the recrystallization layer. The recrystallization layer on the surface of the profile is caused by uneven deformation, which is detrimental to the mechanical properties. Vladivoj et al. [45] indicated that the performance of the recrystallization layer decreases by $25 \%$ compared with the unrecrystallized parts, and the high cycle fatigue life is reduced by more than an order of magnitude. Fan et al. [46] conducted extrusion experiments on 1420 alloy with different process parameters. They found that a higher extrusion ratio and extrusion speed can lead to more recrystallization, and a rapid extrusion speed can reduce the size of subgrain. Chen et al. [47] conducted the extrusion experiments on $2196 \mathrm{Al}-\mathrm{Li}$ alloy under different process parameters and found that increasing the extrusion temperature and extrusion speed can promote DRX and reduce the grain size. The recrystallization degree in the extrusion profile can significantly affect the mechanical properties, for instance, weakening the longitudinal strength and reducing the anisotropy.

In the extrusion process, the orientation of the grains tends to be preferentially distributed, that is, the texture can be formed. It has been proved that the components of texture formed in the profile are greatly affected by extrusion process parameters. Tempus et al. [25, 48] studied the effects of extrusion temperature, extrusion speed, and aspect ratio (width-to-thickness) on the microstructure and mechanical properties of 8090 and $8091 \mathrm{Al}-\mathrm{Li}$ alloy profiles. They found that the aspect ratio has a greater effect on the strength than extrusion temperature and speed. The axisymmetric deformation in the profiles with a low aspect ratio can form the strong $<111>$ and $<100>$ fiber textures, where the $<111>$ texture is dominant. However, the typical rolling textures such as $\operatorname{Br}\{011\}<211>, \mathrm{S}\{123\}<634>$, and $\mathrm{Cu}\{112\}<111>$ can be formed in the profile with a high aspect ratio, in which the deformation tends to be a plane strain. The effect of aspect ratio on texture components has also been found in other Al-Li alloys [27, 29, 31, 32, 49]. Hales et al. [31] found that the $<111>$ and $<100>$ fibers are mainly formed in the low aspect ratio part of the $2195 \mathrm{Al}-\mathrm{Li}$ alloy extrusion profile, while the rolling textures (strong $\mathrm{Br}$ texture) present in the parts with high aspect ratio. Also, a similar phenomenon was found by Goma et al. [29] in the 2099 $\mathrm{Al}-\mathrm{Li}$ alloy extrusion profile.

The texture components have a great influence on the mechanical properties of the profiles. When loaded in the extrusion direction, the $<111>$ and $<100>$ fibers in the extrusion profile have the largest orientation factors (Taylor and Sachs factors), which results in higher strength in the extrusion direction. Therefore, the profiles or parts in profile with the low aspect ratio usually exhibit higher

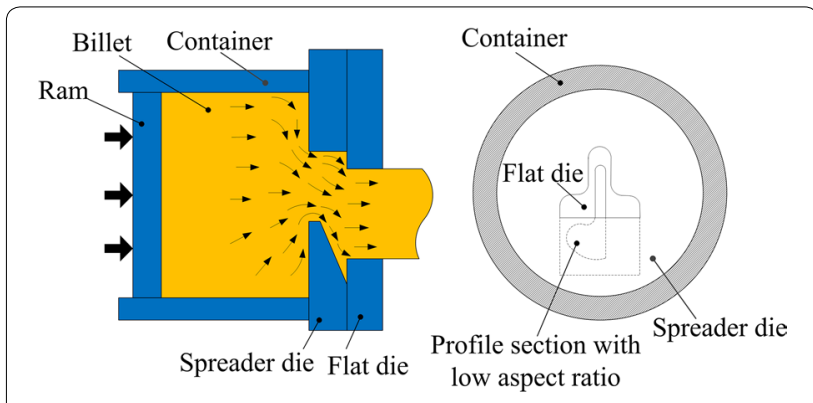

Figure 7 Schematic of the improved extrusion die structure for the profiles with a low aspect ratio (Redraw based on Ref. [50]) 
longitudinal strength. Besides, it has also been found that the components of texture are related to the fatigue crack growth rate. The strong fiber texture and thicker grain layer in the parts with the low aspect ratio have a great inhibition to the crack growth rate [29].

In addition, it is also indicated that the strong fibers will cause a variety of mechanical performance defects, such as the small difference between the tensile and yield strength, low fracture toughness and strong anisotropy of mechanical properties. These defects often cause cracks during the machining of the profiles. To avoid the defects, Armani et al. [34] proposed a new die structure for the extrusion of $\mathrm{Al}-\mathrm{Li}$ alloy profiles. Figure 7 shows the schematic diagram of the extrusion die. They added a spreader die in front of the conventional flat die, which can make the material in the area with low aspect ratio flowing out along the tortuous path, thereby increasing the amount of deformation and improving the performance of the profile. Similar technology was also proposed by Witters et al. [50].

In addition to the aspect ratio, other process parameters will also affect the texture components of the profiles. Jata et al. [51] extruded AF/C489 Al-Li alloy into rectangular plates at different temperatures. They found that strong rolling-textures including $\mathrm{Br}, \mathrm{S}$, and $\mathrm{Cu}$ will be formed in the plate at all extrusion temperatures, whereas the $\mathrm{Br}$ texture increases significantly when the temperature exceeds $480{ }^{\circ} \mathrm{C}$. They believed that the $\mathrm{Br}$ texture is evolved from the shear band during the extrusion process. The fast DRV at the high extrusion temperature of $480{ }^{\circ} \mathrm{C}$ can promote the formation of the shear band, thereby increasing the $\mathrm{Br}$ texture. Chen et al. [47] extruded the $2196 \mathrm{Al}-\mathrm{Li}$ alloy into rectangular plates at different extrusion temperature and speed and found that the shear texture of $\mathrm{Y}\{110\}<111>$ and fiber textures of $\{111\}<$ uvw> (e.g., $A_{1}^{*}$ and $A_{2}^{*}$ ) will be formed in the extrusion processes. The intensity of shear texture reduces as the extrusion temperature increases, and more $\{001\}<100>$ Cube recrystallization texture is formed. Besides, as the extrusion speed increases, the fiber textures become much strong, while the recrystallization texture is suppressed.

In addition, extrusion parameters can also cause a change in solid solubility, which will affect the mechanical properties of the as-extruded profile. For example, the high extrusion temperature and the excessive deformation heat produced by the high extrusion speed can increase the solid solubility and lead to obvious solid solution strengthening effect, which can improve the strength of the as-extruded profile [44, 49]. However, the $\mathrm{Al}-\mathrm{Li}$ alloy profiles are required to be solid solution and aging treated after extrusion, which can largely eliminate the influence of extrusion parameters on the solid solubility and strength of as-extruded profile.

According to the above documents, the influence of extrusion parameters and die structure on the microstructure of profiles is very complex. The effects of various microstructures on mechanical properties cannot be treated as a block. The different microstructure in the extruded profile, such as recrystallization and unrecrystallization as well as various texture components, exhibit different performance characteristics. Therefore, the control of the microstructure during the extrusion process should base on the specific application requirements of the profile. The "customization" of the microstructure should be attempted to achieve through the optimization and innovation of extrusion process and die structure, instead of being restricted to the recrystallization microstructure, anisotropic or isotropic properties.

\subsubsection{Microstructure Prediction and Control during Hot Deformation of the Al-Li Alloys}

The microstructure evolution during hot deformation is closely related to the deformation parameters. Establishing the mathematical model between the deformation parameters and the microstructure can accurately predict the microstructure evolution process and the final state, which is of great significance for controlling and tailoring the microstructure during hot processing.

The models for microstructure evolution during the hot deformation of aluminum alloys have been proposed by many researchers, which mainly include three categories, i.e., the empirical models, physically-based models, and mesoscale discrete models. In the empirical models, the DRX fraction can be predicted by JMAK kinetic equation, and the grain size can be predicted by an exponential equation [52]. Deng et al. [53] established the microstructure evolution model of $2397 \mathrm{Al}-\mathrm{Li}$ alloy based on the JMAK and Kuziak equations and predicted the DRX fraction and grain size of the alloy after hot deformation. The JMAK model is established on the basis of phase transformation theory that includes nucleation and growth processes. Therefore, this kind of model is suitable for prediction of the microstructure evolution in the process of discontinuous dynamic recrystallization (DDRX) that includes obvious nucleation and growth processes. However, the grain evolution in the aluminum alloys usually does occur in the form of continuous dynamic recrystallization (CDRX) without nucleation and growth owing to the high stacking fault energy. And the microstructure after hot deformation is usually an aggregate of crystallites bounded partly by low angle grain boundaries (LAGBs) and partly by high angle grain boundaries (HAGBs), which is very different from the microstructure of DDRX. Figure 8 shows the 

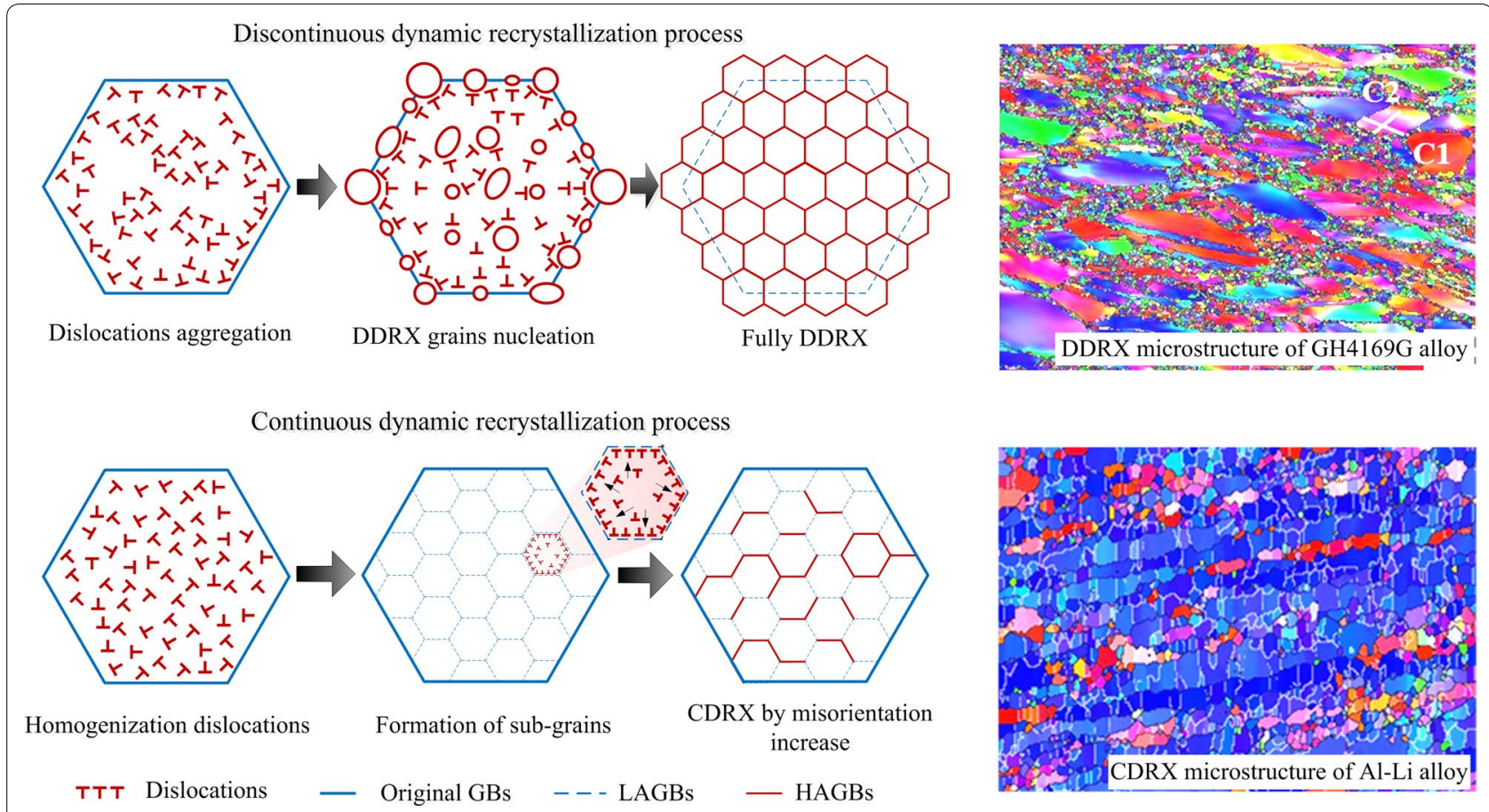

Figure 8 Schematic diagrams for the evolution mechanisms of DDRX and CDRX (The microstructure picture of DDRX was reproduced from Ref. [56])

diagrams for the microstructure evolution of the DDRX and CDRX. Therefore, the theoretical and practical accuracy of the JMAK model in the prediction of aluminum alloy needs to be further investigated and discussed. The mesoscale discrete models including Monte Carlo, cellular automaton, and phase-field simulations have also been used to study the DRX behavior of the aluminum alloys $[54,55]$. However, these methods are also established on the basis of DDRX principles, so that they are still not suitable for the CDRX process.

In recent years, internal state variable (ISV) based microstructural models have drawn attention for modeling the CDRX processes of aluminum alloys. Some microstructure parameters such as dislocation density, crystallite size, misorientation are regarded as the internal state variables in the ISV model, and the actual evolution process of the variables will be considered. This kind of model has a very clear physical meaning and can take into account the mechanism of the microstructure evolution of the CDRX process. Therefore, it is a prospective microstructure evolution model for the materials with high stacking fault energy such as aluminum (lithium) alloys. Gourdet and Montheillet [57] proposed a simple CDRX model based on the assumption that the LAGBs can form and transform into HAGBs by continuously absorbing dislocations. Based on Gourdet's model, Giovanni et al. [58] considered the interaction between particles and dislocations in the alloy and established the CDRX model of 5052 aluminum alloy. Sun et al. [59] integrated the influence of the stored energy in the subgrain boundary on the subgrain rotation into the Gourdet model and considered the different mobility between the recrystallized and original HAGBs, thus further improving the CDRX model. They applied the modified model to the prediction of the microstructure evolution of alloy 7075 during the hot compression deformation. Recently, Chen et al. [60] coupled the CDRX model with the polycrystalline plasticity approach and proposed a new CDRX-VPSC (visco-plastic self-consistent) model, which was successfully used to predict the microstructure evolution of alloy 7075 .

Although the CDRX model based on the internal variable method is consistent with the microstructure evolution mechanism of aluminum alloys, it still faces many difficulties in applying it to the actual extrusion process of the commercial aluminum (lithium) alloys. The commercial alloys usually contain a variety of precipitates due to their complex composition. The interactions between the precipitates with dislocations will cause the complex evolution of dislocation density, which may not be simply described by the ideal model, such as the KME model [61, 62]. Besides, McQueen et al. [63] argued that the assumption of the continuous dislocation absorption in the CDRX model is unrealistic. They believed 
that the misorientation of the LAGBs has a saturation value and the new HAGBs are formed by the geometric dynamic recrystallization (GDRX) of the original grain boundaries. Furthermore, the CDRX model ignores the migration, merging, and decomposition of LAGBs, which will lead to the microstructural evolutions, such as the boundaries proportion, misorientation, and sub-grain size [64-66]. Therefore, the CDRX model needs to be further improved in terms of theoretical completeness.

In many cases, especially in the third generation $\mathrm{Al}-\mathrm{Li}$ alloys, the microstructure in the extruded profiles usually exhibits the fibrous structure without obvious equiaxed recrystallized grains, which is inconsistent with the predicted trend of the CDRX model. Zhang et al. [67] proposed a prediction model for the microstructure mainly composed of fibrous grains in aluminum alloy extrusion profiles, in which they considered and dealt with the recrystallized grains and deformed grains separately. The recrystallization fraction is predicted by the JMAK model, while the grain size is expressed as a function of deformation parameters. The recrystallized and deformed grains are averaged to obtain the final grain size. In terms of the prediction results, this model can accurately describe the grain morphology and size of the aluminum alloy extrusion profile. Nevertheless, the prediction of the recrystallization process in this model still employs the DDRX-based JMAK model.

In addition to the mathematical models, the hot processing map based on the dynamic materials theory is also usually used to predict the micro-mechanism of the hot deformation process and to optimize the process parameters. In the hot process of $\mathrm{Al}-\mathrm{Li}$ alloys, many researchers use the processing map to analyze the deformation mechanism under different parameters and determine the optimal processing parameters. Prasad et al. [3] established the processing maps of the 8090 alloy in three different states including as-casting, as-homogenized, and as-extruded. Micro-mechanisms under different deformation conditions were analyzed on the basis of the processing maps. It was found that the temperature of DRX is the same for the three states of the material, but the corresponding strain rate conditions for the DRX are different. The predicted DRX process parameters range provides important guidance for the forging and rolling processes of the 8090 alloys in different states. Jagan et al. [68] established the hot processing map of the sprayformed $\mathrm{Al}-\mathrm{Li}$ alloy UL40 and predicted the process window for safe deformation. For the third-generation $\mathrm{Al}-\mathrm{Li}$ alloys, Zhang et al. [69], Yin et al. [70], Wang et al. [71] established the processing maps of different alloys and predicted the process parameters range for safe deformation and plastic instability, which provide theoretical guidance for the hot processing of these alloys.

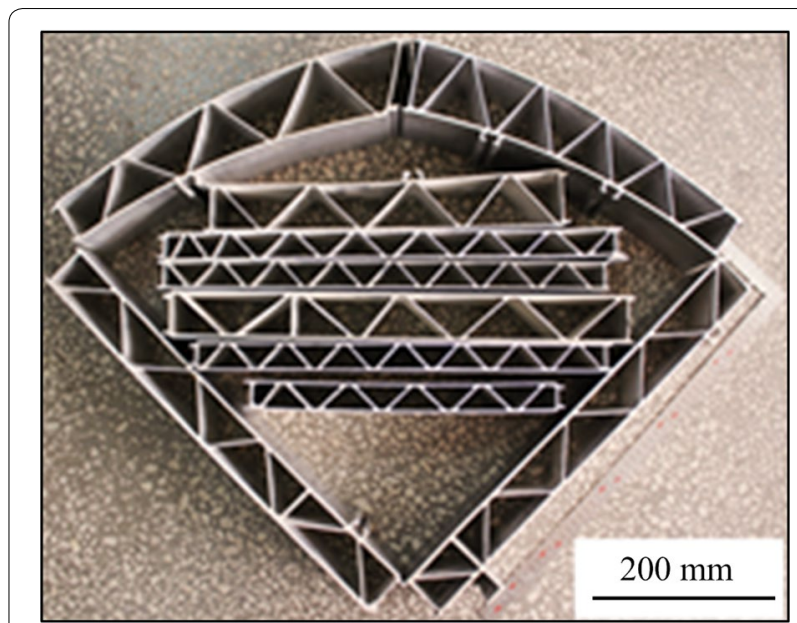

Figure 9 Thin-walled hollow profiles with large and complex cross-sections (Reproduced from Ref. [72])

There are still some problems in the mechanism and prediction accuracy of the existing microstructural models. The conventional JMAK equation is inconsistent with the CDRX mechanism of aluminum alloy, whilst the new internal variable based model has problems in theoretical completeness. The widely used hot processing map reflects the evolution of microstructure from the perspective of energy dissipation based on the stress-strain data, which cannot predict microstructure parameters directly. Therefore, it is necessary to establish a microstructure prediction model that is consistent with CDRX theory and has high prediction accuracy. During the extrusion process, the material is subjected to triaxial compressive stress, and the microstructural evolution is different from other deformation modes such as rolling and forging. Therefore, the deformation characteristics of extrusion should be considered when modeling microstructure evolution.

\subsubsection{Hollow Profile Extrusion of Al-Li Alloys}

Lightweight is the development trend in many fields such as aerospace, high-speed trains, and automobiles. Therefore, there is a growing demand for the thin-walled hollow aluminum (lithium) alloy profiles with large and complex cross-sections (as shown in Figure 9). In addition, many components in aircraft are joined together by welding or riveting, which sometimes forms a hollow structure (as shown in Figure 10). This kind of hollow structure can be formed integrally by portholes extrusion technology, which can decrease the structure weight, reduce the assembly workload, and improve production efficiency. Besides, the integral hollow extrusion components can significantly improve the sealing and overall performance of the aircraft. 


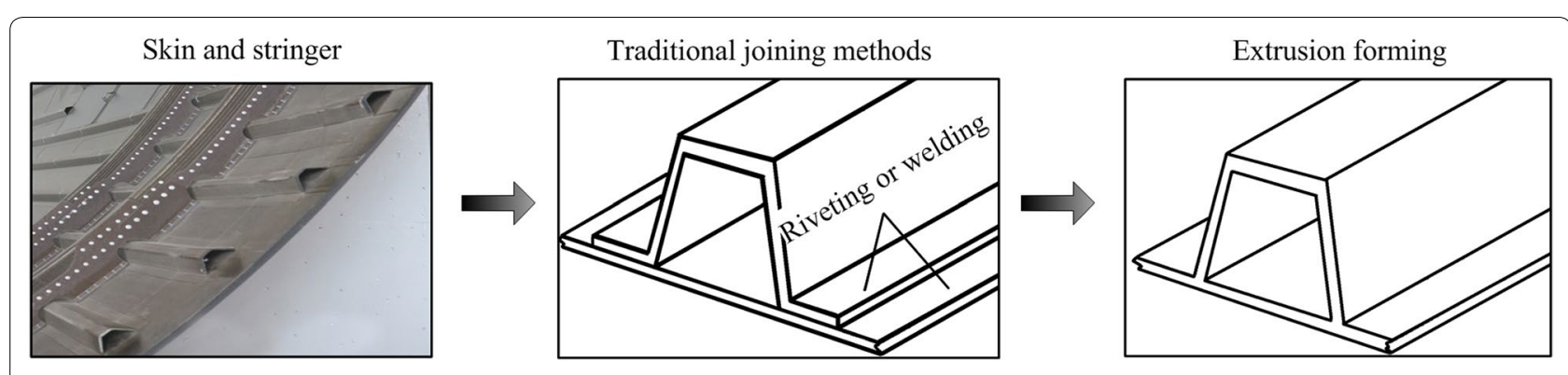

Figure 10 Integrated extrusion process substituting for the riveting and welding

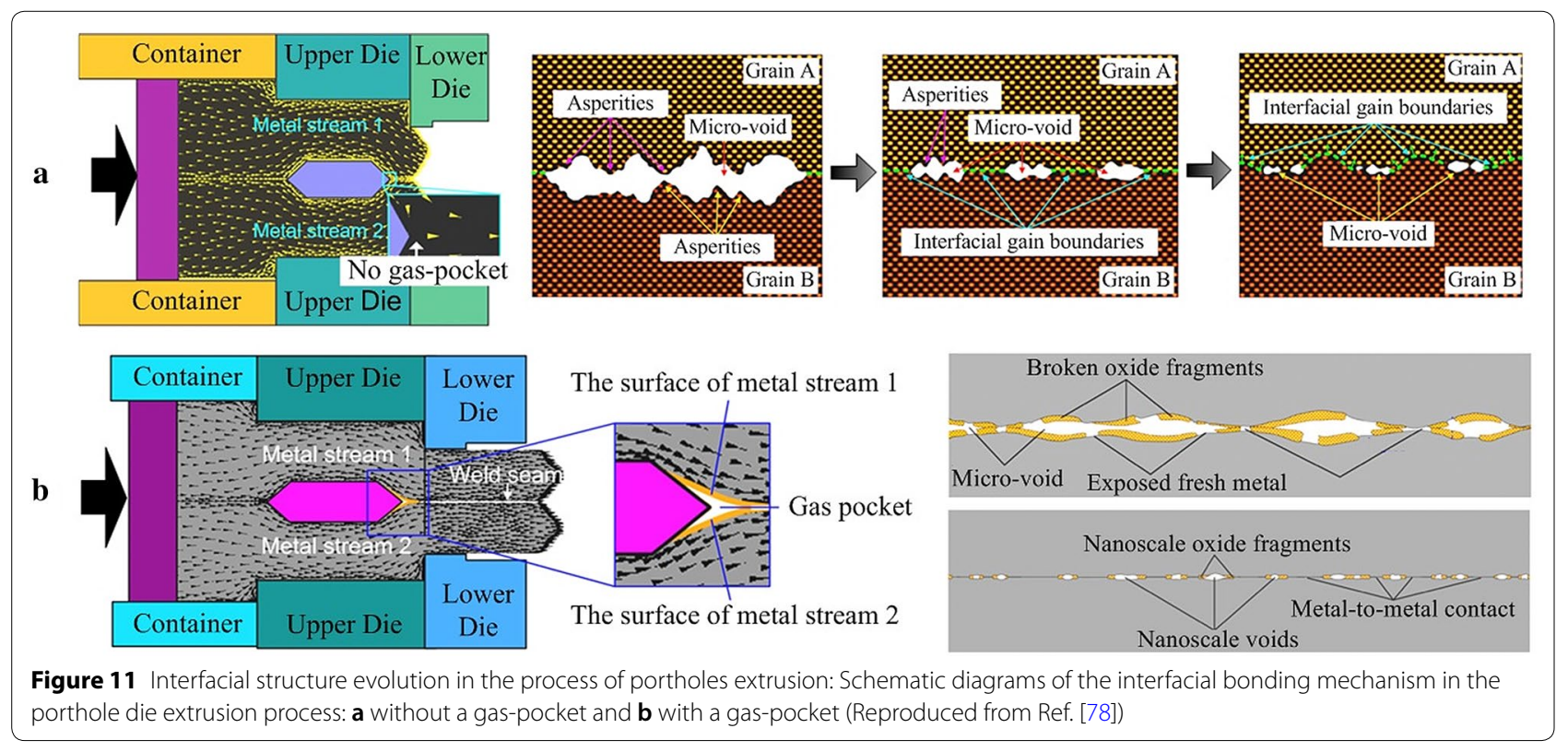

The portholes extrusion process is the common and suitable method used for forming such hollow profiles. The billet is first divided into multiple strands of metal in the portholes, then re-joint in the welding chamber. Finally, the re-jointed material is extruded out through the bearing and die-out and formed into the profile with a hollow section. The overall performance of the hollow profiles depends on the extrusion welding quality of multiple strands of metal in the welding chamber. Therefore, the control of microstructure and performance for the weld seam is the key to obtain good hollow profiles. It is the desired goal that the mechanical properties of the weld seam reach a level close to that of the base material.

Although there are few studies on the extrusion of hollow $\mathrm{Al}-\mathrm{Li}$ alloy profiles, the scientific problems about extrusion welding faced by $\mathrm{Al}-\mathrm{Li}$ alloys should be similar to those faced by aluminum alloys. To date, there have been many reports on the formation and evolution of the weld seam during the porthole extrusion of the aluminum alloys [72-80], which can provide much important guidance for the extrusion of $\mathrm{Al}-\mathrm{Li}$ alloy hollow profiles.

The welding in the portholes extrusion process is essentially a solid welding behavior. The welding quality is mainly affected by the materials bonding degree and the microstructure evolution in the welding area. Figure 11 shows the structure evolution of the welding interface during the extrusion process. There are many microscopic bumps at the welding interface, as shown in Figure 11(a). Under the high temperature and pressure conditions in the welding chamber, the microscopic bumps that are in contact with each other first achieve solid-state welding, which leaves discontinuous microvoids at the welding interface. As the extrusion proceeds, the micro-voids are gradually closed under the combined effects of plastic deformation and diffusion, and a strong bonding is achieved finally. The closing of the micro-voids is the main process of solid-state welding, which largely determines the interface bonding strength. The formation and closing behaviors of micro-voids in 
the extrusion process are greatly affected by the process parameters, die structure, and the material itself. It is of great theoretical significance and application value to study the mechanism of the micro-voids closure and establish a mathematical model for the closure process. At present, the mathematical model of micro-void closure is mainly established for the process of diffusion welding and forging. Based on the plastic deformation and diffusion theory, Ma et al. [81] simplified the shape of the voids at the welding interface into an ellipse and established a mathematical model for the voids closure during diffusion welding. On the basis of the cell model and meso-mechanics approach, Zhang et al. [82] proposed a criterion for void closure during the hot forging of a large ingot and studied the evolution process of the voids. Chen et al. [83] and Feng et al. [84] also studied the influences of void shape, material properties, and process parameters on the void closure process. However, there are few studies on the dynamic evolution of the weld interface structure during the extrusion process. Especially, the closing mechanism of the micro-voids at the extrusion welding interface and its influence on the weld quality need to be investigated in detail.

The welding in the portholes extrusion process sometimes occurs in a non-vacuum environment. In the presence of a gas-pocket behind the bridge, the micro-voids and amorphous layers will co-exist at the bonding interface, as shown in Figure 11(b). In this case, the oxide films on the welding interface need to be first broken to expose the fresh metal. Then the exposed metal contacts each other and bonds together, which leaves the spaced micro-voids and oxide film fragments at the welding interface. As the extrusion proceeds, the residual oxide film continues to break and decompose under the plastic deformation and high temperature. The oxide film on the welding interface can greatly affect the bonding degree, and the final welding quality is also closely related to the processes of the film breaking and decomposition. Yu et al. [78] fabricated the weld seams with and without oxide films by changing the extrusion die structure. They studied the microstructure evolutions and bonding mechanisms of the two kinds of weld interface based on microstructural characterization and finite element analysis. However, the influences of the extrusion parameters on the breaking, decomposition, and final distribution of the oxide film should be investigated furthermore. The breaking and decomposition processes for different thicknesses of the oxide film and their influence on the welding quality also need to be studied.

The microstructure evolution in the welding area has also an important effect on the welding quality. It has been proved that the DRX behavior at the welding
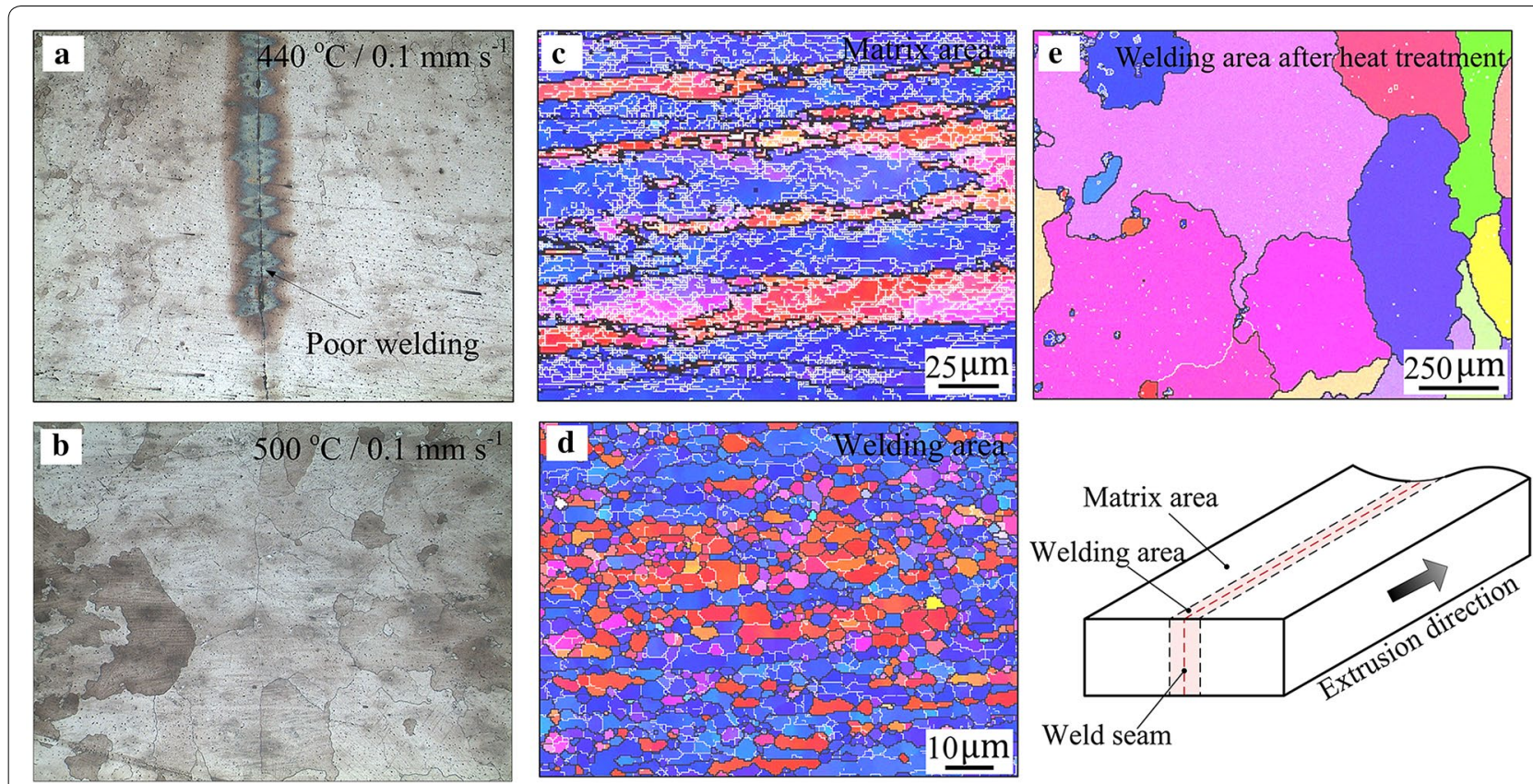

Figure 12 Microstructures of the extrusion welding interface of Al-Li alloy 2195: a, b The bonding degree of welding interfaces at different extrusion temperatures, $\mathbf{c}, \mathbf{d}$ Grain structure of the matrix and welding area, $\mathbf{e}$ Grain structure of welding area after heat treatment (Reproduced from Ref. [89]) 
interface and the grain boundary migration related to the grain growth can promote the bonding of the welding interface, which can significantly improve the welding efficiency [85]. However, the small recrystallized grains formed in the welding area often coarsen or grow abnormally under the high-temperature conditions (including the cooling process after the extrusion and subsequent heat treatment process) $[78,86]$. Besides, the recrystallization process decreases the dislocation density of the welding area, which will reduce the subsequent aging precipitation kinetics. After heat treatment, the coarser grain structure and the less strengthening phase in the welding area will weaken its mechanical properties. Besides, the deformation behavior and microstructure evolution in the welding area are distinct from the base material, which will lead to a difference in grain orientation and grain boundary structure [87].

Recently, Xu et al. $[88,89]$ have conducted the extrusion experiments on $2195 \mathrm{Al}-\mathrm{Li}$ alloy by using portholes die and studied the extrusion welding behavior. Figure 12 shows the microstructure characteristics of the welding area. It can be found that micron-level voids present on the welding interface during extrusion at a low temperature, which is detrimental to the mechanical properties. As the extrusion temperature increases, the voids on the welding interface disappear and relatively good welding can be achieved. Besides, the fine and equiaxed grains can be formed in the welding area due to strong DRX. However, the recrystallized grains coarsen obviously after the solution treatment.

The DRX behavior occurring in the welding area has two opposite effects on the welding quality. On one hand, the DRX can promote the bonding of the welding interface, thus improving the welding efficiency. On the other hand, the DRX will cause obvious grain coarsening and orientation changes, which results in a distinct microstructure between the matrix and welding area and reduces the welding strength. Up to now the mechanisms of recrystallized grains growth across the welding interface and its promotion effect to the interface welding have not been clearly explained. In addition, it is necessary to find an effective method to suppress the coarsening of recrystallized grains in the welding area. The effects of recrystallization on the precipitation behavior and mechanical properties of the welding area are also needed to be studied.

The prediction of welding quality is a common concern in the field of solid-state welding. In order to accurately predict the quality of extrusion welding, several welding criteria have been established based on the normal pressure of the welding surface, such as maximum pressure criterion [90], pressure-time criterion (criterion Q) [79] and pressure-time-flow criterion (criterion K) [80]. By using the established criteria and relevant physical quantities on the welding interface, the welding quality of longitudinal weld seam in the hollow profile can be predicted [91, 92], which can greatly improve the optimization efficiency of the die structure and process parameters. The influences of pressure, equivalent stress, material flow speed, and contact time on the welding quality are mainly considered in the above welding criteria. However, Edwards et al. [93], Cooper et al. [94], and Bariani et al. [95] studied the welding process by using physical simulation experiments and found that other factors such as temperature and strain also have a significant impact on the welding quality. Yu et al. [72] proposed a welding criterion based on triaxial stress, equivalent strain rate, temperature, and contact time by comprehensively considering the influences of plastic deformation and diffusion on the closing behavior of micro-voids at the welding interface. This welding criterion has been successfully applied to predict the longitudinal welding quality of a hollow aluminum profile and exhibited higher prediction accuracy than the previous criteria. As for the extrusion of $\mathrm{Al}-\mathrm{Li}$ alloy hollow profiles, it is also necessary to establish an appropriate welding criterion and an evaluation method of welding quality based on the material characteristics and the welding behavior of $\mathrm{Al}-\mathrm{Li}$ alloy.

\subsection{Heat Treatments of Al-Li Alloy Extrusion Profile 4.3.1 Solid Solution and Quenching Processes}

The extruded $\mathrm{Al}-\mathrm{Li}$ alloy profiles need to be solution treated and quenched to prepare the microstructure for the subsequent aging treatment. The solution temperature and time have important effects on the solubility of the secondary particles, dispersion of solutes, static recrystallization behavior, and grain growth.

The common solution treatments include single and double-stage processing. Compared with the singlestage solution, the two-stage solution treatment can effectively increase the solutes supersaturation, which promotes precipitation during the aging process. And the two-stage solid solution is more effective to the large workpiece [96]. In addition, the quenching after solution treatment has a significant effect on the microstructure and mechanical properties of the $\mathrm{Al}-\mathrm{Li}$ alloys. Gable and Csontos et al. [97, 98] conducted quenching experiments on $\mathrm{AF} / \mathrm{C} 458$ and $\mathrm{AF} / \mathrm{C} 489 \mathrm{Al}-\mathrm{Li}$ alloys at different quenching rates. They found that the samples with a slow quenching rate exhibit high quenching strength, but the strength increase after the aging treatment is small. The samples with a fast quenching rate can be strengthened greatly after the aging process, 
and a better toughness can be obtained by the faster quenching rate.

As the aerospace structural components, the requirement on mechanical properties of $\mathrm{Al}-\mathrm{Li}$ alloy extrusion profiles is higher than that on the conventional aluminum alloy profiles. Therefore, the solid solution and quenching treatments of the $\mathrm{Al}-\mathrm{Li}$ alloy profiles typically employ a more secure offline processing. However, there are two problems in the offline solution and quenching processes, which are particularly prominent for the second-generation $\mathrm{Al}-\mathrm{Li}$ alloy profiles [99]. Firstly, the solute $\mathrm{Li}$ in the profile will migrate to the surface during a long time solid solution at high temperature, which will lead to a decrease of Li content in the profiles, especially in the thin-walled ones. The precipitation of the strengthening phases in the subsequent aging process will be weakened by the reduction in $\mathrm{Li}$ content. Secondly, the element $\mathrm{Li}$ migrating to the profile surface will react with oxygen and water vapor to form Lithium hydroxide which can cause the corrosive pitting on the surface. Besides, long time solution treatment at a high temperature will also lead to dislocation recovery and grain growth, which have a negative impact on the mechanical properties of the profiles. The problem of corrosive pitting can be solved by using a salt bath or applying the high-temperature coatings on the profile surface. However, the migration of $\mathrm{Li}$ and the decrease of dislocation density fail to be addressed by the methods. In order to settle the problems, Jarrett et al. [99] proposed the online quenching technology for extrusion of the $\mathrm{Al}-\mathrm{Li}$ alloys with a specific composition containing more than $1.5 \mathrm{wt} . \%$ lithium and more than 0.5 wt.\% copper. These kinds of alloys have a high extrudable temperature (that is above the solution temperature) and low quench sensitivity, therefore the quenching online can be realized by adjusting the extrusion temperature and speed. However, the extrusion temperature for the third-generation $\mathrm{Al}-\mathrm{Li}$ alloys is usually lower than their solution temperature, and the quenching sensitivity is high. Therefore, it is required to modify the extrusion equipment by adding external heating and rapid cooling devices to realize the online quenching of the third generation alloys.

The above problems are mainly caused by the high temperature and the long treatment time of solution treatment. Therefore, shortening the solution time is a way to avoid the problem. Xu et al. [100] found an electropulsing treatment can make the second-phase rapidly dissolve into the matrix in the alloy 7075 , and the sample treated

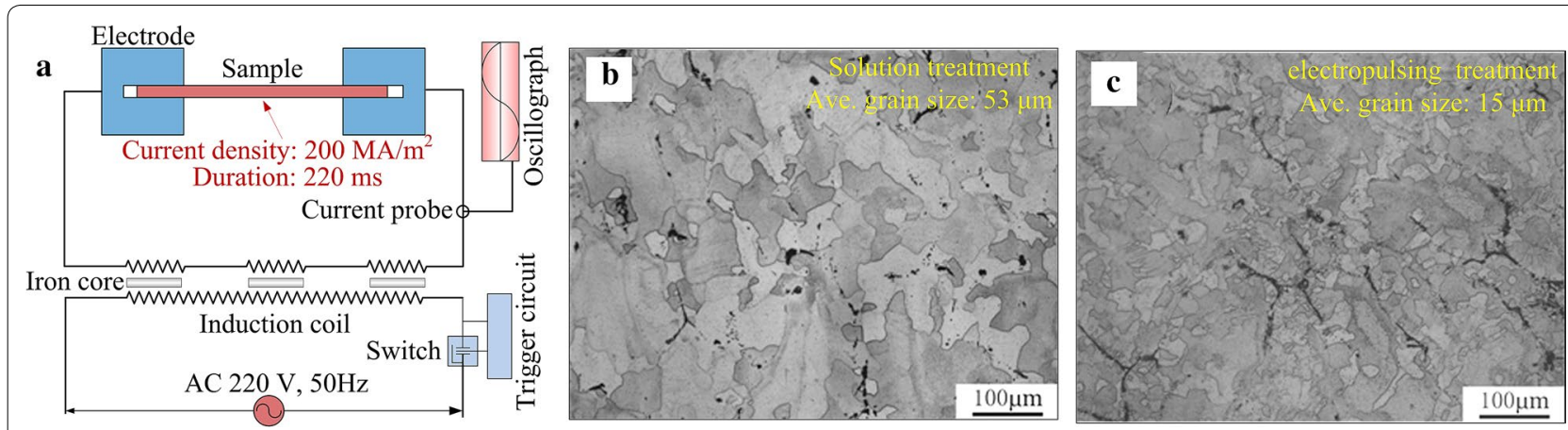

Figure 13 Electropulsing treatment method and result: a schematic illustration for the electropulsing system (Redraw based on Ref. [101]), b microstructure after conventional solution treatment, and c electropulsing treatment (Reproduced from Ref. [100])

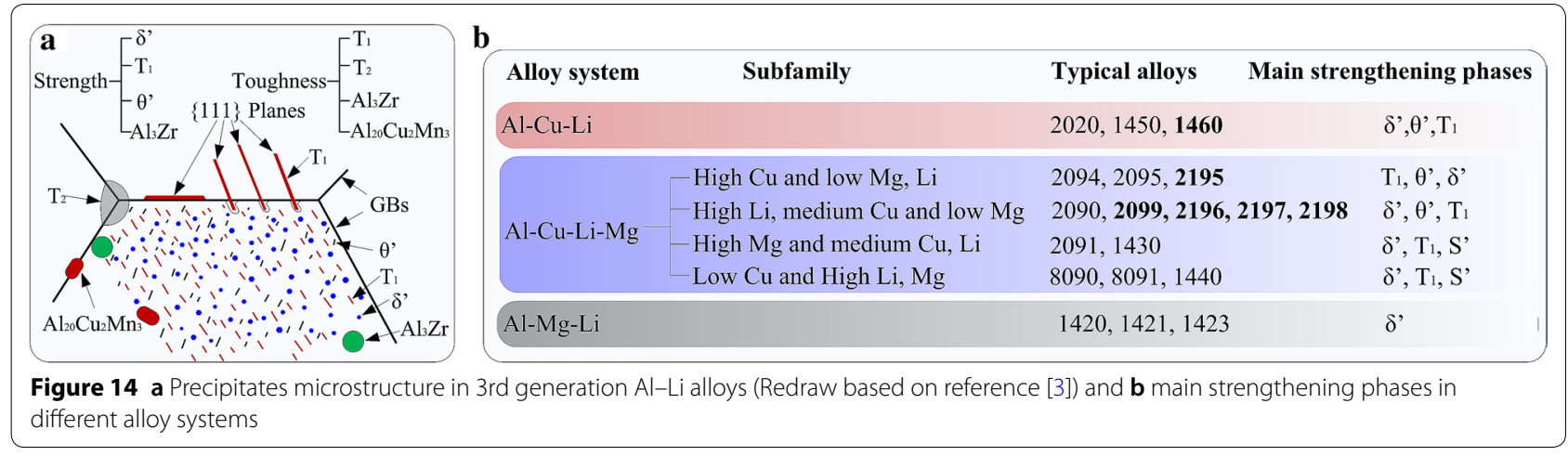


Table 3 Common precipitates in Al-Li alloys and their crystal structure information [3, 102, 103]

\begin{tabular}{|c|c|c|c|c|}
\hline Precipitates & Lattice types & Lattice constants (nm) & Orientation relationships & Characteristics \\
\hline$\theta^{\prime \prime}\left(\mathrm{Al}{ }_{2} \mathrm{Cu}\right)$ & Tetragonal & $a=0.404, c=0.78$ & $\begin{array}{l}(100)_{\mathrm{Al}} / /(100)_{\theta^{\prime \prime}} \\
{[001]_{\mathrm{Al}} / / /[001]_{\theta^{\prime \prime}}}\end{array}$ & Coherent, plate-like \\
\hline$\theta^{\prime}\left(\mathrm{Al}_{2} \mathrm{Cu}\right)$ & Tetragonal & $a=0.404, c=0.58$ & $\begin{array}{l}(100)_{\mathrm{Al}} / /(100)_{\theta^{\prime}} \\
{[001]_{\mathrm{Al}} / /\left[[001]_{\theta^{\prime}}\right.}\end{array}$ & Semi-coherent, lath-like \\
\hline$\delta^{\prime}\left(\mathrm{Al}_{3} \mathrm{Li}\right)$ & Cubic $\left(L 1_{2}\right)$ & $a=0.401$ & Cube-Cube & Coherent, ordered, spherical and metastable \\
\hline$\delta(A l L i)$ & Cubic (B32) & $a=0.637$ & $\begin{array}{l}(100)_{\mathrm{Al}} / /(100)_{\delta} \\
(111)_{\mathrm{Al}} / /(011)_{\delta}\end{array}$ & Incoherent, spherical \\
\hline $\mathrm{T}_{1}\left(\mathrm{Al}_{2} \mathrm{CuLi}\right)$ & Hexagonal & $a=0.497, c=0.935$ & $\begin{array}{l}(111)_{\mathrm{Al}_{\mathrm{II}} / /(0001)_{\mathrm{T}_{1}}}[2111]_{\mathrm{Al}} / /[1120]_{\mathrm{T}_{1}} \\
{[110]_{\mathrm{Al}} / / /[1010]_{\mathrm{T}_{1}}}\end{array}$ & Semi-coherent, plate-like \\
\hline $\mathrm{T}_{\mathrm{B}}\left(\mathrm{Al}_{7.5} \mathrm{Cu}_{4} \mathrm{Li}\right)$ & Cubic $\left(\mathrm{CaF}_{2}\right)$ & $a=0.583$ & $\begin{array}{l}(110)_{\mathrm{Al}} / /(100)_{\mathrm{T}_{\mathrm{B}}} \\
(001)_{\mathrm{Al}} / /(001)_{\mathrm{T}_{\mathrm{B}}}\end{array}$ & Lath-like \\
\hline $\mathrm{T}_{2}\left(\mathrm{Al}_{6} \mathrm{CuLi}_{3}\right)$ & Cubic (Uncertainty) & $a=1.391$ & - & Icosahedral symmetry \\
\hline $\mathrm{S}^{\prime} / \mathrm{S}\left(\mathrm{Al}_{2} \mathrm{CuMg}\right)$ & Orthorhombic & $a=0.401, b=0.925 ; c=0.715$ & $\begin{array}{l}(100)_{\mathrm{Al}} / /(100)_{S^{\prime}} \\
{[021]_{\mathrm{Al}} / / /[010]_{S^{\prime}}} \\
{[012]_{\mathrm{Al}} / /[001]_{S^{\prime}}}\end{array}$ & Semi-coherent, rod or plate-like \\
\hline$\beta^{\prime}\left(\mathrm{Al}_{3} \mathrm{Zr}\right)$ & Cubic $\left(\mathrm{L}_{2}\right)$ & $a=0.405$ & Cube-Cube & Coherent, ordered, spherical and dispersed \\
\hline$\Omega\left(\mathrm{Al}_{2} \mathrm{Cu}\right)$ & Orthorhombic & $a=0.496, b=0.856, c=0.848$ & $\begin{array}{l}(211)_{\mathrm{Al}} / /(100)_{\Omega} \\
(110)_{\mathrm{Al}} / /(010)_{\Omega} \\
(11)_{\mathrm{Al}} / /(001)_{\Omega}\end{array}$ & Thin plate-like \\
\hline$\sigma\left(\mathrm{Al}_{5} \mathrm{Cu}_{6} \mathrm{Mg}_{2}\right)$ & Cubic & $a=0.827$ & - & Incoherent, square block \\
\hline
\end{tabular}

with electropulsing and aging exhibits higher strength than that of conventional T6 treatment. Figure 13 shows the schematic illustration of the electropulsing system and comparison after conventional solution treatment and electropulsing treatment. It can be seen that the secondary phases have been dissolved into the matrix after a very short period of electropulsing treatment, and the grain size is significantly smaller than the conventional solution treatment. The electropulsing treatment provides a direction for the rapid solution of $\mathrm{Al}-\mathrm{Li}$ alloys. It is worthwhile to study and look forward to the application of rapid solution methods with additional energy fields in Al-Li alloys.

\subsubsection{Aging Strengthening of Al-Li Alloys}

(1) Precipitates of Al-Li Alloys

The extruded profiles of Al-Li alloy need to be aged to obtain the required strength and toughness. The precipitation behavior of the $\mathrm{Al}-\mathrm{Li}$ alloys is mainly affected by the aging parameters, i.e., aging temperature and time. The types of precipitates as well as their size and distribution can be controlled by the aging parameters and will affect the mechanical properties significantly. Figure 14 shows the precipitates microstructure in the 3rd generation $\mathrm{Al}-\mathrm{Li}$ alloys and main strengthening phases in dif- ferent alloy systems $[1,3,17]$. The precipitates and their crystalline structure information are given in Table 3.

(2) Aging process of $\mathrm{Al}-\mathrm{Li}$ alloys

Aging treatment is the main strengthening method for $\mathrm{Al}-\mathrm{Li}$ alloys. Therefore, the aging process has always received much attention throughout the developments of the first, second, and third-generation $\mathrm{Al}-\mathrm{Li}$ alloys. The researches include the aging precipitation mechanism, the effect of aging parameters on the precipitation behavior, and the optimization of aging process parameters [1, 3, 9, 104]. Because of the large number of researches in this field, only the aging processes widely used in the third-generation Al-Li alloys are introduced here. In addition, based on the requirement of the aging process optimization for the extrusion profiles, the prediction models of aging strengthening will be also introduced briefly.

Compared with the second generation $\mathrm{Al}-\mathrm{Li}$ alloys, the $\mathrm{Li}$ content in the third-generation $\mathrm{Al}-\mathrm{Li}$ alloys is significantly reduced, which inhibits the precipitation of $\delta$ ' phase. Meanwhile, the elements $\mathrm{Mg}$ and $\mathrm{Ag}$ are added to the alloys to promote the precipitation of $\mathrm{T}_{1}$ as the dominant strengthening phase. The plate-like $\mathrm{T}_{1}$ phase precipitated on the $\{111\}_{\mathrm{Al}}$ plane can effectively homogenize slip, which is useful to improve the toughness and reduce the anisotropy. It has been proved that the dislocations in 

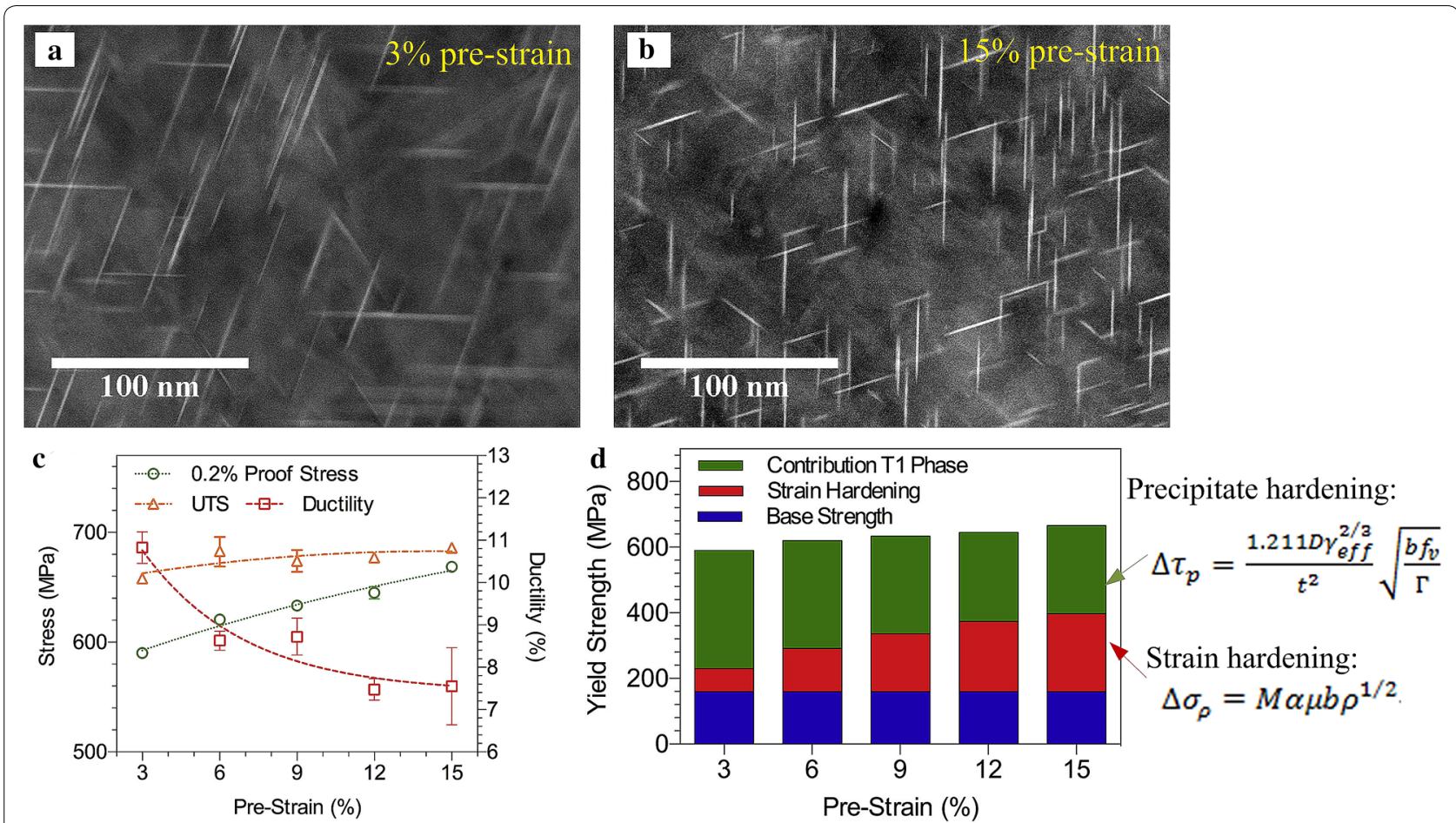

Figure 15 Ageing precipitation in 2195 alloy after: a 3\% pre-strain, b 15\% pre-strain, c the mechanical properties with different pre-strain, d quantitative analysis of strength contributions from the precipitate and strain hardening (Reproduced from Ref. [108])

the matrix can act as the heterogeneous nucleation sites of the $T_{1}$ phase, so that promote the precipitation in dense and uniform [105, 106]. Kim et al. [107] carried out various aging treatments on 2195 alloy plates and found that the precipitate $T_{1}$ is the main strengthening phase, which can improve significantly the strength of the alloy. Rodgers et al. [108] carried out different pre-stretching on alloy 2195 and studied the quantitative relationships among the pre-stretching degree, precipitation, and strength increment. They found that larger prestrain results in finer and denser precipitation of the $\mathrm{T}_{1}$ phase as well as a greater strain hardening effect. With the increase of pre-strain, the contribution of strain hardening to strength increases gradually, while the contribution from precipitates decreases, as shown in Figure 15. According to the nucleation mechanism of the $\mathrm{T}_{1}$ phase, the mechanical properties of the $\mathrm{Al}-\mathrm{Li}$ alloy products such as extrusion profiles and rolling plates can be improved by predeformation before aging treatment.

Sometimes, it is difficult to apply the pre-deformation into the complex components owning to the shape restriction. Therefore, it is required to develop an aging process without pre-deformation, which can increase the strength to the same level as the pre-deformation treatment. Many studies have shown that dense precipitation can also be achieved through the two-stage or multi-stage aging process including a low-temperature aging and the following high-temperature aging treatments. The solution-treated alloy is first pre-aged at a low temperature so that the solute elements aggregate at the defects to form the GP zones or metastable phase. Then the aging is performed at a high temperature to precipitate the fine and uniform strengthening phase [109]. Rioja et al. [110] studied the twostage aging process of 2090 and 8090 Al-Li alloys and found that the high strength and good toughness of the alloy can be obtained by the low-temperature aging at $93{ }^{\circ} \mathrm{C}$ and the high-temperature aging at $219^{\circ} \mathrm{C}$. By optimizing the multi-stage aging processes for $\mathrm{Al}-\mathrm{Li}$ alloy 2099, Romios et al. [111] improved the mechanical properties and reduced its anisotropy.

(3) Aging Hardening Model

The number, size, and distribution of the precipitates in the matrix have a decisive effect on the mechanical properties of the alloy, whilst the precipitation characteristics are closely related to the aging temperature, time, and material composition. Therefore, establishing the quantitative relation- 
ship between the aging process parameters and alloy strength can accurately predict the strength increase of the alloy in the aging process, which is of great significance to the reasonable design of the aging process for the extrusion profiles and other products. The aging strength predication model includes two parts, i.e., the models for the precipitation evolution and the models for precipitation strengthening. By coupling the precipitation and strengthening models, the yield strength of the alloy after aging treatment can be predicted according to the aging parameters.

In the model of precipitation strengthening, the strength increments resulted from solutes, precipitates, dislocations, and grain boundaries are needed to be considered separately, and then these increments are synthesized according to a strength superposition method to calculate the total strengthening increment. The strengthening caused by the solutes is often simply expressed as a power function of the solutes' concentration $[112,113]$. According to the morphology and characteristic of the precipitates, there are mainly six kinds of precipitation strengthening mechanisms, including chemical strengthening, stacking fault strengthening, modulus strengthening, coherent strengthening, ordered strengthening, and geometric strengthening. Ardell discussed the above strengthening mechanisms in his review paper and summarized the mathematical models for these strengthening effects [114]. The main precipitates in $\mathrm{Al}-\mathrm{Li}$ alloys include non-spherical phases $\mathrm{T}_{1}$, $\theta$,' and $S^{\prime}$ as well as the spherical phase $\delta$. The first three phases are often considered as non-shearable when calculating their strength contributions, while the latter one is regarded as the shearable phase. By comprehensively considering the size, distribution, and orientation of the precipitates, Zhu et al. [115] established strengthening models for the unshearable phases with spherical, rod-shaped, and platelike shapes, which can predict the strength increase caused by the phases $\mathrm{T}_{1}, \theta^{\prime}$ and $\mathrm{S}^{\prime}$. However, Dorin et al. [116] indicated that the main strengthening phase $\mathrm{T}_{1}$ in $\mathrm{Al}-\mathrm{Cu}-\mathrm{Li}$ alloy can be cut by dislocations. They proposed a strengthening model for the shearable $T_{1}$ phase based on the strengthening of interfacial energy and stacking fault energy and successfully predicted the strength evolution of the 2198 alloy in the range from under-aging to overaging treatments.

On the basis of the previous models, Starink et al. [117] presented the general expression of the strengthening model of the shearable precipitates, in which only the order strengthening mechanism was considered. The strengthening caused by the solute clusters or GP zones precipitated in the early aging stage can be quantitatively described by the mathematical model proposed by Cartaud et al. [118]. In addition to the solution and precipitation strengthening, the hindering effect of the (sub-) grain boundaries on the dislocation movement and the interaction between dislocations can also cause an increase in strength. Grain boundary strengthening is usually described by the classical relationship of Hall-Petch, while the strengthening caused by dislocations is proportional to the square root of the dislocation density [119]. The total strength increase caused by the different strengthening mechanisms needs to be calculated by appropriate superposition rules. The common way is to superimpose linearly the solution and grain size strengthening, while the dislocation and precipitation strengthening are superimposed in the form of Pythagorean [119-121].

There are three general approaches to model precipitation kinetics, including the physical-based numerical model, ISV-based analytical model, and numerical model based on size discrete. The latter two models have been summarized and discussed in detail in Ref. [122]. In the ISV-based analytical model, the classical nucleation and growth theories, such as the empirical JMAK equation and LSW coarsening law, are used to calculate the precipitation fraction and particle size. Some researchers also calculated the precipitation density and average particle size during the precipitation process through the differential ISV-based analytical model [119]. In the ISV-based analytical model, the growth and coarsening processes are considered to be isolated from each other. And this model can only describe the precipitation process involving a precipitation phase or a diffusion mechanism. In recent years, the KWN numerical model proposed by Kampmann and Wagner [123] has attracted much attention in modeling the precipitation kinetics. In this model, the precipitates are classified into a series of discrete classes according to their size. The precipitates in the same class have identical variables. By using the same formulation, the size distribution of precipitates can be obtained by calculating the precipitates changes in each class at every time step [122, 124]. The KWN model couples the processes of nucleation, growth, and coarsening of precipitates, thus solving the problem that the ISVbased analytical model cannot be applied to multicomponent alloys. This model has been applied to 
several aluminum alloys such as $\mathrm{Al}-\mathrm{Si}-\mathrm{Mg}$ alloy, $\mathrm{Al}-\mathrm{Zn}-\mathrm{Mg}$ alloy, and $\mathrm{Al}-\mathrm{Cu}-\mathrm{Mg}$ alloy [121, 124, 125], and also described the precipitation process of multi-component alloys through coupling with CALPHAD software $[126,127]$. However, there is currently no report on the application of the KWN model in commercial aluminum-lithium alloys. The precipitation behavior of $\mathrm{Al}-\mathrm{Li}$ alloys is complex. During the aging process, the phases with different components precipitate competitively, and the types of precipitates will change in the process of non-isothermal aging. Therefore, it is difficult to establish the precipitation kinetics model of commercial Al-Li alloys.

\section{Summary and Prospect}

In this paper, the extrusion processing of $\mathrm{Al}-\mathrm{Li}$ alloy profiles and related scientific and technological researches are summarized and analyzed, mainly including the applications and performances, the extrusion process, the influences of extrusion and heat treatment processes on the microstructure and performance. At present, there are relatively few reports about the extrusion technology of $\mathrm{Al}-\mathrm{Li}$ alloys, especially the third generation alloys. It is necessary to investigate theoretical aspects of the new extrusion process and die structure, microstructure and performance control of extrusion profile, and extrusion of hollow Al-Li alloy profile, and provide the theoretical guidelines for practical extrusion process and die design. According to the review and analysis of the current researches, the following aspects would be the focus of future research on $\mathrm{Al}-\mathrm{Li}$ alloy extrusion technology.

1. The microstructural evolution during the extrusion process of $\mathrm{Al}-\mathrm{Li}$ alloys and the active control technology of extrusion profiles microstructure. The extrusion process and die structure determine the microstructures of the Al-Li alloy profiles, such as the texture component and intensity as well as the degree of recrystallization, which has significant effects on the properties of the profiles. The microstructure evolution of the third-generation Al-Li alloys during the extrusion needs to be further investigated. Besides, there are different requirements for the properties of $\mathrm{Al}-\mathrm{Li}$ alloy profiles in different applications. In order to meet the various performance requirements, the active control of the microstructure during the extrusion should be attempted by optimizing and innovating the extrusion process and die structure.

2. The microstructure prediction model for the extrusion process of $\mathrm{Al}-\mathrm{Li}$ alloys. The conventional micro- structure prediction model based on the DDRX principle is not suitable for the CDRX process of aluminum (lithium) alloys. The new CDRX model has problems in its own theoretical completeness and conformity with the extrusion microstructure, which is difficult to predict the microstructure evolution during the extrusion process of $\mathrm{Al}-\mathrm{Li}$ alloy. Therefore, it is necessary to establish a microstructure evolution model for the extrusion process, which can meet the evolution mechanism of CDRX and can also accurately describe the microstructural features of the extrusion profile. Besides, the texture evolution during the extrusion process of Al-Li alloys has a significant impact on the mechanical properties of the profile. Therefore, the prediction of texture evolution in the process of extrusion is also a problem that needed to be solved.

3. The extrusion welding behavior of Al-Li alloys and the prediction model of welding quality. The control and prediction of weld quality are one of the keys to the extrusion of hollow profiles. It can be known that the closing of the micro-voids, the breaking and decomposition of the oxide film, and the microstructural evolution in the welding area are the important factors of the welding quality. Therefore, the first problems that should be concerned and solved for extrusion of hollow Al-Li alloy profiles include the extrusion welding behavior, the mechanisms of micro-voids closure and oxide film breaking and decomposition, and the microstructure evolution in the welding area. It is also necessary to find an effective method to suppress the coarsening and abnormal growth of grains in the welding area. Besides, the accurate prediction model of welding quality suitable for the Al-Li alloys is also needed to be established, which is important for the design and optimization of the extrusion process and die structure for the hollow Al-Li alloy profiles.

4. Rapid solid solution process for the Al-Li alloys. A long time solution treatment for the thin-walled $\mathrm{Al}-\mathrm{Li}$ alloy profiles will lead to a decrease in Li content and corrosive pitting on the surface, which will reduce the aging strength and surface quality of the profiles. The reduction of dislocation density and grain coarsening will also occur during the long time solution treatment, which will cause a reduction in mechanical properties. Shortening the solution time is one way to solve the above problems. It has been proved that the high-energy electric pulse can complete the solution treatment of the alloy 7075 in a very short time. Therefore, it is worthwhile to study and look forward to the application of rapid solution methods with additional energy fields in Al-Li alloys. 
5. The aging strengthening model of the Al-Li alloys. By using the accurate aging strengthening model, the precipitation and the resulting strengthening increment under different aging processes can be predicted, which is of great significance for the design and optimization of the aging process of $\mathrm{Al}-\mathrm{Li}$ alloy profiles. The precipitation behavior of commercial $\mathrm{Al}-\mathrm{Li}$ alloys is very complicated during the aging process, which makes it difficult to model the precipitation kinetics. To obtain the outstanding mechanical properties, the pre-stretching and non-isothermal aging treatments are often used for the $\mathrm{Al}-\mathrm{Li}$ alloy profiles. The aging prediction model is more critical for the optimization of the complex aging processes. However, in the processes of the pre-stretching and non-isothermal aging, precipitation behavior becomes more complicated by the influence of dislocations and changing temperatures. Therefore, it is important and challenging to establish an aging precipitation model suitable for the extrusion profiles of commercial Al-Li alloys.

6. Research and development of new Al-Li alloy with excellent mechanical properties as well as good plastic formability. Compared with the conventional aluminum alloys, $\mathrm{Al}-\mathrm{Li}$ alloys tend to exhibit poor extrudability, and the range of the process parameters is narrow. Therefore, it is necessary to develop new $\mathrm{Al}-\mathrm{Li}$ alloys with both high formability and good mechanical properties. Large-scale integral panel extrusions and complex extrusions with the hollow section are the development direction of the extrusion structure in the aerospace field. The new $\mathrm{Al}-\mathrm{Li}$ alloys with good formability can meet the forming needs of the complex extrusion profiles. In addition, the extrusion process of the new $\mathrm{Al}-\mathrm{Li}$ alloys profiles, including the extrusion processing parameters, the material flow, and die deformation, are required to be studied.

\section{Acknowledgements \\ Not applicable}

\section{Authors' Contributions}

YW: Conceptualization, Writing materials collection and sorting, Visualization, Writing-Original draft preparation. GZ: Content planning, Funding acquisition, Resources, Revising and Editing. Both authors read and approved the final manuscript.

\section{Authors'Information \\ Yongxiao Wang, born in 1990, is currently a PhD candidate at Shandong Uni- versity, China. He received his master degree from Shandong University of Sci- ence and Technology, China, in 2016. His research interests include aluminum alloy extrusion, numerical modeling and die optimal design. Tel: +86-531- 88392811; E-mail:wangyongxiao@mail.sdu.edu.cn.}

Guoqun Zhao, born in 1962, is currently a professor at Shandong University, China. He received his PhD degree from Shanghai Jiao Tong University, China, in 1992. His research interests include forging, extrusion, injection molding, numerical modeling and optimal design. Tel: +86-531-88393238; E-mail: zhaogq@sdu.edu.cn.

\section{Funding}

Supported by National Science Foundation of China (Grant No. 51735008) and Shandong Province Major scientific and Technological Innovation Project of China (Grant No. 2019TSLH0102).

\section{Competing Interests}

The authors declare no competing financial interests.

Received: 12 June 2020 Revised: 31 July 2020 Accepted: 17 August 2020 Published online: 11 September 2020

\section{References}

[1] R J Rioja, J Liu. The evolution of Al-Li base products for aerospace and space applications. Metallurgical and Materials Transactions A, 2012, 43(9): 3325-3337.

[2] E A Starke, JT Staley. Application of modern aluminum alloys to aircraft. Progress in Aerospace Sciences, 1996, 32: 131-172.

[3] N E Prasad, E A Gokhale, R J H Wanhill. Aluminum-lithium alloys: Processing, properties, and applications. Oxford: Butterworth-Heinemann, 2013.

[4] L P Huang, Z Q Zheng, Y P Huang. Microstructure and properties of $2197 \mathrm{Al}-\mathrm{Li}$ alloy. The Chinese Journal of Nonferrous Metals, 2004, 14(12): 2066-2072. (in Chinese)

[5] X L Wu, M Liu, J X Zang, et al. Research progress and aerospace application of aluminum lithium alloys. Materials Review, 2016, 30(S2): 571-578. (in Chinese)

[6] E A Starke, F S Lin. The influence of grain structure on the ductility of the Al-Cu-Li-Mn-Cd alloy 2020. Metallurgical Transactions A, 1982, 13(12): 2259-2269.

[7] N E Prasad, A A Gokhale, P R Rao. Mechanical behaviour of aluminiumlithium alloys. Sadhana, 2003, 28(1-2): 209-246.

[8] J C Williams, E A Starke. Progress in structural materials for aerospace systems. Acta Materialia, 2003, 51(19): 5775-5799.

[9] $\mathrm{X} L \mathrm{Wu}, \mathrm{M} \mathrm{Liu}, \mathrm{G} A \mathrm{Li}$, et al. Research and progress of thermomechanical treatment of Al-Li alloys. Journal of Aeronautical Materials, 2016, 36(5): 82-89. (in Chinese)

[10] C H Zhai, C H Feng, L H Chai, et al. Development of Al-Li alloy and a new type of Al-Li alloy X2A66. Journal of Material Sciences and Engineering, 2015, 33(2): 302-306. (in Chinese)

[11] K K Cho, Y H Chung, CW Lee, et al. Effects of grain shape and texture on the yield strength anisotropy of Al-Li alloy sheet. Scripta Materialia, 1999, 40(6): 651-657.

[12] N Jiang, X Gao, Z Q Zheng. Microstructure evolution of aluminumlithium alloy 2195 undergoing commercial production. Transactions of Nonferrous Metals Society of China, 2010, 20(5): 740-745.

[13] J Hirsch, O Engler, K Lucke, et al. The rolling texture development in an 8090 Al-Li alloy. Le Journal de Physique Colloques, 1987, 48(C3): 605-611.

[14] Y Xie, Y Deng, Y Wang, X Guo. Effect of asymmetric rolling and subsequent ageing on the microstructure, texture and mechanical properties of the Al-Cu-Li alloy. Journal of Alloys and Compounds, 2020, 836: 155445

[15] M C Y Niu. Airframe structural design: Practical design information and data on aircraft structures. Hong Kong, China: Conmilit, 2002.

[16] J X Huang, H Wang. Aircraft structures design and analysis. Shanghai: Shanghai Jiaotong University Press, 2012. (in Chinese)

[17] A Abd El-Aty, Y Xu, X Guo, et al. Strengthening mechanisms, deformation behavior, and anisotropic mechanical properties of Al-Li alloys: A review. Journal of Advanced Research, 2018, 10: 49-67.

[18] M J Birt, M S Domack, R A Hafley, et al. Characterization of Al-Cu-Li alloy 2090 near net shape extrusion. NASA, 1998. https://ntrs.nasa.gov/searc h.jsp?R=19980197316.

[19] PJ Hartley. Production of Aluminum-Lithium near net shape extruded cylinders. NASA, 1995. https://ntrs.nasa.gov/search.jsp?R=19960003743.

[20] JT Staley. Advances in aluminium alloy products for structural applications in transportation. Journal De Physique IV, 1993, 3(C7): 179-190. 
[21] XT Song, Y J Lei. Experimental study on mechanical properties of 1420cs Al-Li alloy moulding material. Journal of National University of Defense Technology, 2002, 24(2): 14-16. (in Chinese)

[22] MHSkillingberg, RF Ashton. Processing and performance of Al-Li-Cu-X extrusions. Le Journal De Physique Colloques, 1987, 48(C3): 179-186.

[23] ED Sweet, C G Bennett, I Musulin, et al. Effects of alkali-metal impurities on fracture toughness of $2090 \mathrm{Al}-\mathrm{Li}$-Cu extrusions. Metallurgical and Materials Transactions A, 1996, 27(11): 3530-3541.

[24] C G Bennett, S P Lynch, R B Nethercott, et al. Fracture toughness of 2090 $\mathrm{Al}-\mathrm{Li}-\mathrm{Cu}$ extrusions with high and low hydrogen contents. Materials Science and Engineering A, 1998, 247(1): 32-39.

[25] GTempus, W Calles, G Scharf. Influence of extrusion process parameters and texture on mechanical properties of Al-Li extrusions. Materials Science and Technology, 1991, 7(10): 937-946.

[26] A Bois-Brochu, F A T Goma, C Blais, et al. Al-Li alloy 2099-T83 extrusions: static mechanical properties, microstructure and texture. Advanced Materials Research, 2011, 409: 29-34.

[27] A Bois-Brochu, C Blais, F A T Goma, et al. Characterization of Al-Li 2099 extrusions and the influence of fiber texture on the anisotropy of static mechanical properties. Materials Science and Engineering A, 2014, 597: 62-69.

[28] F A T Goma, D Larouche, A Bois-Brochu, et al. Fatigue crack growth behavior of 2099-T83 extrusions in two different environments. 13th International Conference on Aluminum Alloys, The Minerals, Metals \& Materials Society, Pittsburgh, 2012.

[29] F A T Goma, D Larouche, A Bois-Brochu, et al. Effect of extrusion aspect ratio and test temperatures on fatigue crack growth behavior of a 2099-T83 Al-Li alloy. International Journal of Fatigue, 2014, 59: 244-253.

[30] W Wang, Y J Wang, T J Liu, et al. Tensile properties of 2099 and 2196 A1-Li alloy extrusions. Aerospace Materials and Technology, 2014, 44(4): 55-59. (in Chinese)

[31] S J Hales, R A Hafley. Texture and anisotropy in Al-Li alloy 2195 plate and near-net-shape extrusions. Materials Science and Engineering $A$, 1998, 257(1): 153-164

[32] Q Zhang, C Zhang, J Lin, et al. Microstructure analysis and low-cycle fatigue behavior of spray-formed Al-Li alloy 2195 extruded plate. Materials Science and Engineering A, 2019, 742: 773-787.

[33] S Kumar, H B Mcshane, T Sheppard. Effect of extrusion parameters on the microstructure and properties of an Al-Li-Mg-Zr alloy. Journal of Materials Science, 1994, 29(4): 1067-1074.

[34] KP Armanie, P Hills, R J Rioja, et al. Extrusion of aluminum-lithium alloys: US, 6113711. 2000-09-05. https://patents.google.com/patent/US611 3711/en.

[35] MV Kharitonovich, KF Zhu. Manufacture of large size panels and shape materials from high strength $\mathrm{Al}$ and $\mathrm{Al}-\mathrm{Li}$ alloys. Journal of Materials Engineering, 1994, 3: 4-8. (in Chinese)

[36] F Zhang, J Shen, X Yan, et al. Homogenization heat treatment of 2099 Al-Li alloy. Rare Metals, 2014, 33(1): 28-36.

[37] HY Li, X J Su, H Yin, et al. Microstructural evolution during homogenization of Al-Cu-Li-Mn-Zr-Ti alloy. Transactions of Nonferrous Metals Society of China, 2013, 23(9): 2543-2550.

[38] M Jia, Z Zheng, Z Gong. Microstructure evolution of the $1469 \mathrm{Al}-\mathrm{Cu}-\mathrm{Li}$ Sc alloy during homogenization. Journal of Alloys and Compounds, 2014, 614: 131-139.

[39] Y Wang, G Zhao, X Xu, et al. Microstructures and mechanical properties of spray deposited $2195 \mathrm{Al}-\mathrm{Cu}$-Li alloy through thermo-mechanical processing. Materials Science and Engineering A, 2018, 727: 78-89.

[40] J J Xu, M Jiang. Homogenization treatment to optimize the microstructures of the $\mathrm{Al}-3.5 \mathrm{Cu}-1.5 \mathrm{Li}$ alloy and analysis of $\mathrm{Al}_{3} \mathrm{Zr}$ precipitates. Materials Science Forum, 2018, 921: 195-201.

[41] CXiong, M Jiang, J Xu. Effects of homogenization process on precipitation of $\mathrm{Al}_{3} \mathrm{Zr}$ and recrystallization resistance in $\mathrm{Al}-\mathrm{Cu}-\mathrm{Li}$ - $\mathrm{Zr}$ alloy. IOP Conference Series: Earth and Environmental Science, 2018, 186: 12051.

[42] Z H Jia, J P Couzinie, N Cherdoudi, et al. Precipitation behaviour of $\mathrm{Al}_{3} \mathrm{Zr}$ precipitate in $\mathrm{Al}-\mathrm{Cu}-\mathrm{Zr}$ and $\mathrm{Al}-\mathrm{Cu}-\mathrm{Zr}-\mathrm{Ti}-\mathrm{V}$ alloys. Transactions of Nonferrous Metals Society of China, 2012, 22(8): 1860-1865.

[43] DTsivoulas, J D Robson. Heterogeneous $\mathrm{Zr}$ solute segregation and $\mathrm{Al}_{3} \mathrm{Zr}$ dispersoid distributions in Al-Cu-Li alloys. Acta Materialia, 2015, 93: 73-86.
[44] A K Mukhopadhyay, H M Flower, T Sheppard. Development of microstructure in AA 8090 alloy produced by extrusion processing. Materials Science and Technology, 1990, 6(5): 461-468.

[45] V Očenášek, P Sedláček. The effect of surface recrystallized layers on properties of extrusions and forgings from high strength aluminium alloys. 20th International Conference on Metallurgy and Materials, Brno, Czech Republic, 2011.

[46] Y Q Fan, Y X Wang. Extrusion characteristics of $1420 \mathrm{Al}-\mathrm{Li}$ alloy. The 3rd National Conference on Aluminum-Lithium Alloys, Chongqing, 1996. (in Chinese)

[47] X Chen, G Zhao, G Liu, et al. Microstructure evolution and mechanical properties of $2196 \mathrm{Al}-\mathrm{Li}$ alloy in hot extrusion process. Journal of Materials Processing Technology, 2020, 275: 116348.

[48] G Tempus, G Scharf, W Calles. Influence of extrusion process parameters on the mechanical properties of Al-Li extrusions. Le Journal de Physique Colloques, 1987, 48(C3): 187-193.

[49] Y Wang, G Zhao, X Chen, et al. Effect of inter-annealing between two stages of extrusion on the microstructure and mechanical property for spray deposited Al-Cu-Li alloy 2195. Journal of Materials Research and Technology, 2019, 8(5): 3891-3907.

[50] J J Witters, B A Cheney, R J Rioja. Low aspect ratio lithium-containing aluminum extrusions: US, 5151136, 1992-09-29. https://patents.googl e.com/patent/US5151136A/en.

[51] KV Jata, S Panchanadeeswaran, A K Vasudevan. Evolution of texture, microstructure and mechanical property anisotropy in an Al-Li-Cu alloy. Materials Science and Engineering A, 1998, 257(1): 37-46.

[52] M Pietrzyk, L Cser, J G Lenard. Mathematical and physical simulation of the properties of hot rolled products. Oxford: Elsevier, 1999.

[53] L Deng, J S Jin, J C Xia, et al. Study on microstructure evolution of 2397 aluminum alloy during hot deformation. The 12th National Annual Conference on Plastic Engineering, Chongqing, 2011. (in Chinese)

[54] J Li, Z Xie, S Li, Y Zang, Modeling on dynamic recrystallization of aluminium alloy 7050 during hot compression based on cellular automaton. Journal of Central South University, 2016, 23(3): 497-507.

[55] M A Miodownik. A review of microstructural computer models used to simulate grain growth and recrystallisation in aluminium alloys. Journal of Light Metals, 2002, 2(3): 125-135.

[56] D Jia, W Sun, D Xu, et al. Dynamic recrystallization behavior of GH4169G alloy during hot compressive deformation. Journal of Materials Science \& Technology, 2019, 35(9): 1851-1859.

[57] S Gourdet, F Montheillet. A model of continuous dynamic recrystallization. Acta Materialia, 2003, 51(9): 2685-2699.

[58] G Maizza, R Pero, M Richetta, et al. Continuous dynamic recrystallization (CDRX) model for aluminum alloys. Journal of Materials Science, 2018, 53(6): 4563-4573.

[59] ZC Sun, H L Wu, J Cao, et al. Modeling of continuous dynamic recrystallization of Al-Zn-Cu-Mg alloy during hot deformation based on the internal-state-variable (ISV) method. International Journal of Plasticity, 2018, 106: 73-87.

[60] SF Chen, DY Li, S H Zhang, et al. Modelling continuous dynamic recrystallization of aluminum alloys based on the polycrystal plasticity approach. International Journal of Plasticity, 2020, 131: 102710.

[61] H Mecking, U F Kocks. Kinetics of flow and strain-hardening. Acta Metallurgica, 1981, 29(11): 1865-1875.

[62] Y Estrin, $\mathrm{H}$ Mecking. A unified phenomenological description of work hardening and creep based on one-parameter models. Acta Metallurgica, 1984, 32(1): 57-70.

[63] H J McQueen, M E Kassner. Comments on'a model of continuous dynamic recrystallization' proposed for aluminum. Scripta Materialia, 2004, 51(5): 461-465.

[64] E Nes. Hot deformation behaviour of particle-stabilized structures in Zr-bearing Al alloys. Metal Science, 1979, 13(3-4): 211-215.

[65] H Zhang, L Li, D Yuan, et al. Hot deformation behavior of the new AlMg-Si-Cu aluminum alloy during compression at elevated temperatures. Materials Characterization, 2007, 58(2): 168-173.

[66] J L Wan, X J Sun, J L Gu, et al. Research on continuous dynamic recrystallization in hot torsion of Al-Cu-Mg-Zn-Cr alloy. Acta Metallurgica Sinica, 1999, 72(2): 413-457. (in Chinese)

[67] C Zhang, CWang, R Guo, et al. Investigation of dynamic recrystallization and modeling of microstructure evolution of an Al-Mg-Si aluminum 
alloy during high-temperature deformation. Journal of Alloys and Compounds, 2019, 773: 59-70.

[68] G J Reddy, N Srinivasan, A A Gokhale, et al. Processing map for hot working of spray formed and hot isostatically pressed Al-Li alloy (UL40). Journal of Materials Processing Technology, 2009, 209(18-19): 5964-5972.

[69] F Zhang, J L Sun, J Shen, et al. Flow behavior and processing maps of 2099 alloy. Materials Science and Engineering A, 2014, 613: 141-147.

[70] H Yin, H Li, X Su, et al. Processing maps and microstructural evolution of isothermal compressed $\mathrm{Al}-\mathrm{Cu}-\mathrm{Li}$ alloy. Materials Science and Engineering A, 2013, 586: 115-122.

[71] Y Wang, G Zhao, X Xu, et al. Constitutive modeling, processing map establishment and microstructure analysis of spray deposited Al-Cu-Li alloy 2195. Journal of Alloys and Compounds, 2019, 779: 735-751.

[72] J Yu, G Zhao, L Chen. Analysis of longitudinal weld seam defects and investigation of solid-state bonding criteria in porthole die extrusion process of aluminum alloy profiles. Journal of Materials Processing Technology, 2016, 237: 31-47.

[73] YT Kim, K Ikeda, T Murakami. Metal flow in porthole die extrusion of aluminium. Journal of Materials Processing Technology, 2002, 121(1): 107-115.

[74] A J den Bakker, R J Werkhoven, W H Sillekens, et al. The origin of weld seam defects related to metal flow in the hot extrusion of aluminium alloys EN AW-6060 and EN AW-6082. Journal of Materials Processing Technology, 2014, 214(11): 2349-2358.

[75] J Yu, G Zhao, L Chen. Investigation of interface evolution, microstructure and mechanical properties of solid-state bonding seams in hot extrusion process of aluminum alloy profiles. Journal of Materials Processing Technology, 2016, 230: 153-166.

[76] F Gagliardi, T Citrea, G Ambrogio, et al. Influence of the process setup on the microstructure and mechanical properties evolution in porthole die extrusion. Materials \& Design, 2014, 60: 274-281.

[77] HValberg. Extrusion welding in aluminium extrusion. International Journal of Materials and Product Technology, 17(7): 497-556.

[78] JYu, G Zhao. Interfacial structure and bonding mechanism of weld seams during porthole die extrusion of aluminum alloy profiles. Materials Characterization, 2018, 138: 56-66

[79] M Plata, J Piwnik. Theoretical and experimental analysis of seam weld formation in hot extrusion of aluminum alloys. Proceedings of Seventh International Aluminum Extrusion Technology Seminar, Chicago, 2000.

[80] L Donati, L Tomesani. The prediction of seam welds quality in aluminum extrusion. Journal of Materials Processing Technology, 2004, 153-154: 366-373.

[81] R Ma, M Li, H Li, et al. Modeling of void closure in diffusion bonding process based on dynamic conditions. Science China-Technological Sciences, 2012, 55(9): 2420-2431.

[82] X Zhang, Z Cui, W Chen, et al. A criterion for void closure in large ingots during hot forging. Journal of Materials Processing Technology, 2009, 209(4): 1950-1959.

[83] M Chen, Y C Lin. Numerical simulation and experimental verification of void evolution inside large forgings during hot working. International Journal of Plasticity, 2013, 49: 53-70.

[84] C Feng, Z Cui. A 3-D model for void evolution in viscous materials under large compressive deformation. International Journal of Plasticity, 2015, 74: $192-212$

[85] L Zhou, S Feng, M Sun, et al. Interfacial microstructure evolution and bonding mechanisms of 14YWT alloys produced by hot compression bonding. Journal of Materials Science \& Technology, 2019, 35: 1671-1680.

[86] J Tang, L Chen, G Zhao et al. Formation mechanism of abnormal coarse grains on weld seam of extruded ZK60 alloy and the effects on mechanical properties. Materials Science and Engineering A, 2020, 773 : 138718.

[87] J Yu, G Zhao, C Zhang, et al. Dynamic evolution of grain structure and micro-texture along a welding path of aluminum alloy profiles extruded by porthole dies. Materials Science and Engineering A, 2017, 682: 679-690.

[88] XXu, G Zhao, Y Wang, et al. Microstructural evolution and its effect on mechanical properties of spray deposited 2195 alloy during porthole die extrusion process. Vacuum, 2019, 167: 28-39.

[89] XXu, G Zhao, S Yu, et al. Effects of extrusion parameters and post-heat treatments on microstructures and mechanical properties of extrusion weld seams in $2195 \mathrm{Al}-\mathrm{Li}$ alloy profiles. Journal of Materials Research and Technology, 2020, 9(3): 2662-2678.

[90] R Akeret. Properties of pressure welds in extruded aluminium alloy sections. Journal of the Institute of Metals, 1972, 10: 202.

[91] V Güley, A Güzel, A Jäger, et al. Effect of die design on the welding quality during solid state recycling of AA6060 chips by hot extrusion. Materials Science and Engineering A, 2013, 574: 163-175.

[92] G Liu, J Zhou, J Duszczyk. FE analysis of metal flow and weld seam formation in a porthole die during the extrusion of a magnesium alloy into a square tube and the effect of ram speed on weld strength. Journal of Materials Processing Technology, 2008, 200(1-3): 185-198.

[93] S P Edwards, A J den Bakker, J Zhou, et al. Physical simulation of longitudinal weld seam formation during extrusion to produce hollow aluminum profiles. Materials and Manufacturing Processes, 2009, 24(4): 409-421.

[94] D R Cooper, J M Allwood. The influence of deformation conditions in solid-state aluminium welding processes on the resulting weld strength. Journal of Materials Processing Technology, 2014, 214(11): 2576-2592.

[95] P F Bariani, S Bruschi, A Ghiotti. Physical simulation of longitudinal welding in porthole-die extrusion. CIRP Annals-Manufacturing Technology, 2006, 55(1): 287-290.

[96] Y Wu, X J Xu, Z Q Zhang et al. Solution treatment of $2099 \mathrm{Al}-\mathrm{Li}$ alloy with Sr and Sc additives. Heat Treatment of Metals, 2013, 38(4): 40-44. (in (hinese)

[97] B M Gable, A A Csontos, E A Starke. A quench sensitivity study on the novel Al-Li-Cu-X alloy AF/C 458. Journal of Light Metals, 2002, 2(2): 65-75.

[98] A A Csontos, B M Gable, A Gaber, et al. The effect of quench rate on the microstructure and properties of AF/C-458 and AF/C-489 Al-Li-Cu-X alloys. Materials Science Forum, 2000, 331-337: 1333-1340.

[99] M R Jarrett. Production of extruded aluminum-lithium alloys: US, 5820708, 1998-10-13. https://patents.google.com/patent/US5820708A/ en.

[100] $X X u, Y Z$ Zhao, $X$ Wang, et al. Effect of rapid solid-solution induced by electropulsing on the microstructure and mechanical properties in 7075 Al alloy. Materials Science and Engineering A, 2016, 654: 278-281.

[101] X Xu, Y Zhao, B Ma, et al. Rapid precipitation of T-phase in the 2024 aluminum alloy via cyclic electropulsing treatment. Journal of Alloys and Compounds, 2014, 610: 506-510.

[102] S L Yang. Study on hot deformation behavior and microstructure, property of 2297 Al-Li alloy. Beijing: General Research Institute for Nonferrous Metals, 2016. (in Chinese)

[103] SC Wang, M J Starink. Precipitates and intermetallic phases in precipitation hardening Al-Cu-Mg-(Li) based alloys. International Materials Reviews, 2005, 50(4): 193-215.

[104] Z Q Zheng, J F Li, Z G Chen, et al. Alloying and microstructural evolution of Al-Li alloys. The Chinese Journal of Nonferrous Metals, 2011, 21(10): 2337-2351. (in Chinese)

[105] W A Cassada, G J Shiflet, E A Starke. The effect of plastic deformation on $\mathrm{Al}_{2} \mathrm{CuLi}\left(\mathrm{T}_{1}\right)$ precipitation. Metallurgical Transactions A, 1991, 22(2): 299-306.

[106] B M Gable, A W Zhu, A A Csontos, et al. The role of plastic deformation on the competitive microstructural evolution and mechanical properties of a novel Al-Li-Cu-X alloy. Journal of Light Metals, 2001, 1(1): 1-14.

[107] J Kim, J Jeun, H Chun, et al. Effect of precipitates on mechanical properties of AA2195. Journal of Alloys and Compounds, 2016, 669: 187-198.

[108] B I Rodgers, P B Prangnell. Quantification of the influence of increased pre-stretching on microstructure-strength relationships in the $\mathrm{Al}-\mathrm{Cu}-\mathrm{Li}$ alloy AA2195. Acta Materialia, 2016, 108: 55-67.

[109] K Stiller, P J Warren, V Hansen, et al. Investigation of precipitation in an $\mathrm{Al}-\mathrm{Zn}-\mathrm{Mg}$ alloy after two-step ageing treatment at $100^{\circ}$ and $150^{\circ} \mathrm{C}$. Materials Science and Engineering A, 1999, 270(1): 55-63.

[110] R J Rioja, E L Colvin, Vasudevan, et al. Aluminum alloy two-step aging method and article: US, 4861391, 1989-08-29. https://patents.googl e.com/patent/US4861391A/en.

[111] M Romios, RTiraschi, C Parrish, et al. Design of multistep aging treatments of 2099 (C458) Al-Li alloy. Journal of Materials Engineering and Performance, 2005, 14(5): 641-646. 
[112] M J Starink, N Gao, L Davin, et al. Room temperature precipitation in quenched Al-Cu-Mg alloys: a model for the reaction kinetics and yield strength development. Philosophical Magazine, 2005, 85(13): 1395-1417.

[113] HR Shercliff, M F Ashby. A process model for age hardening of aluminium alloys-II. Applications of the model. Acta Metallurgica et Materialia, 1990, 38(10): 1803-1812.

[114] A J Ardell. Precipitation hardening. Metallurgical Transactions A, 1985, 16(12): 2131-2165.

[115] A W Zhu, E A Starke. Strengthening effect of unshearable particles of finite size: a computer experimental study. Acta Materialia, 1999, 47(11): 3263-3269.

[116] T Dorin, A Deschamps, F D Geuser, et al. Quantification and modelling of the microstructure/strength relationship by tailoring the morphological parameters of the $\mathrm{T}_{1}$ phase in an Al-Cu-Li alloy. Acta Materialia, 2014, 75: 134-146.

[117] M J Starink, P Wang, I Sinclair, et al. Microstrucure and strengthening of Al-Li-Cu-Mg alloys and MMCs: II. Modelling of yield strength. Acta Materialia, 1999, 47(14): 3855-3868.

[118] L Cartaud, J Guillot, J Grilhe. Proceedings of the Fourth International Conference on the Strength of Metals and Alloys, Nancy, France, 1976, 1:214

[119] A Deschamps, Y Brechet. Influence of predeformation and ageing of an Al-Zn-Mg alloy-II. Modeling of precipitation kinetics and yield stress. Acta Materialia, 1998, 47(1): 293-305.
[120] C Genevois, A Deschamps, A Denquin, et al. Quantitative investigation of precipitation and mechanical behaviour for AA2024 friction stir welds. Acta Materialia, 2005, 53(8): 2447-2458.

[121] I N Khan, M J Starink, J L Yan. A model for precipitation kinetics and strengthening in Al-Cu-Mg alloys. Materials Science and Engineering A, 2008, 472(1-2): 66-74.

[122] X N Wang, L Z Han, J F Gu. Aging precipitation kinetics and strengthening models for aluminum alloys. The Chinese Journal of Nonferrous Metals, 2013, 23(10): 2754-2768. (in Chinese)

[123] R Wagner, R Kampmann. Phase transformations in materials. In: R W Cahn, P Haasen, EJ Kramer. Materials science and technology: a comprehensive treatment, Wiley-VCH, 1991.

[124] R Chen, Q Xu, H Guo, et al. Modeling the precipitation kinetics and tensile properties in Al-7Si-Mg cast aluminum alloys. Materials Science and Engineering A, 2017, 685: 403-416.

[125] N Kamp, A Sullivan, R Tomasi, et al. Modelling of heterogeneous precipitate distribution evolution during friction stir welding process. Acta Materialia, 2006, 54(8): 2003-2014.

[126] Q Du, W J Poole, M A Wells. A mathematical model coupled to CALPHAD to predict precipitation kinetics for multicomponent aluminum alloys. Acta Materialia, 2012, 60(9): 3830-3839.

[127] L Rougier, A Jacot, C Gandin, et al. Numerical simulation of precipitation in multicomponent Ni-base alloys. Acta Materialia, 2013, 61(17): 6396-6405.

\section{Submit your manuscript to a SpringerOpen ${ }^{\odot}$ journal and benefit from:}

- Convenient online submission

- Rigorous peer review

- Open access: articles freely available online

- High visibility within the field

- Retaining the copyright to your article

Submit your next manuscript at $\boldsymbol{\nabla}$ springeropen.com 